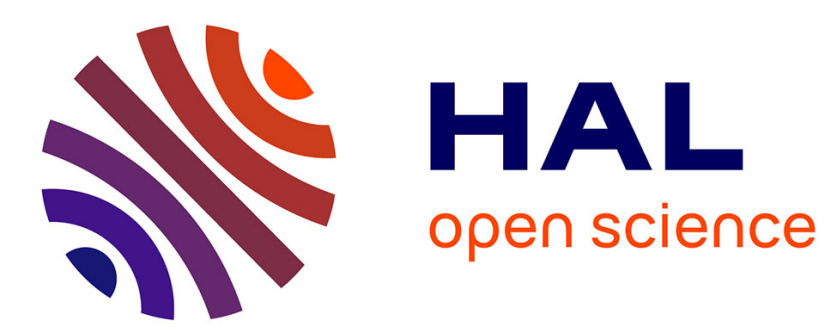

\title{
Centrifuge modeling of batter pile foundations under sinusoidal dynamic excitation
}

Zheng Li, Sandra Escoffier, Panagiotis Kotronis

\section{To cite this version:}

Zheng Li, Sandra Escoffier, Panagiotis Kotronis. Centrifuge modeling of batter pile foundations under sinusoidal dynamic excitation. Bulletin of Earthquake Engineering, 2016, 14 (3), pp.673-697. 10.1007/s10518-015-9859-2 . hal-01300250

\section{HAL Id: hal-01300250 \\ https://hal.science/hal-01300250}

Submitted on 11 Nov 2019

HAL is a multi-disciplinary open access archive for the deposit and dissemination of scientific research documents, whether they are published or not. The documents may come from teaching and research institutions in France or abroad, or from public or private research centers.
L'archive ouverte pluridisciplinaire HAL, est destinée au dépôt et à la diffusion de documents scientifiques de niveau recherche, publiés ou non, émanant des établissements d'enseignement et de recherche français ou étrangers, des laboratoires publics ou privés. 


\title{
Centrifuge modeling of batter pile foundations under earthquake excitation
}

\author{
Zheng $\mathrm{Li}^{\mathrm{a}, \mathrm{b}, *}$, Sandra Escoffier ${ }^{\mathrm{a}}$, Panagiotis Kotronis ${ }^{\mathrm{b}}$ \\ a IFSTTAR, GERS, SV, F-44341 Bouguenais, France \\ ${ }^{\mathrm{b}}$ Ecole Centrale de Nantes, Université de Nantes, CNRS, Institut de Recherche en Génie Civil et Mécanique (GeM), 1 Rue de la Noë, F-44321 Nantes, France
}

\begin{abstract}
Although batter pile foundations are widely used in civil engineering structures, their behavior under seismic loadings is not yet thoroughly understood. This paper provides insights about the differences in the behavior of batter and vertical piles under seismic soil-pile-superstructure interaction. An experimental dynamic centrifuge program is presented, where the influences of the base shaking signal and the height of the gravity center of the superstructure are investigated. Various seismic responses are analyzed (displacement and rotation of the pile cap, total shear force at the pile cap level, overturning moment, residual bending moment, total bending moment and axial forces in piles). It is found that in certain cases batter piles play a beneficial role on the seismic behavior of the pile foundation system. The performance of batter piles depends not only on the characteristics of the earthquakes (frequency content and amplitude) but also on the type of superstructures they support. This novel experimental work provides a new experimental database to better understand the behavior of batter pile foundations in seismic regions.
\end{abstract}

\section{Introduction}

Batter piles, also called inclined or raked piles, are widely used in civil engineering constructions where substantial lateral resistance is required. However, many building codes or standards like AFPS 1990 [1] and Eurocode-8 [2] do not recommend the use of batter piles in seismic regions. Although less conservative, codes like ACI318-05 and ACI318-11 recommend to pay attention to the potential damages at the junction of the batter piles and the superstructure. The main drawbacks of the batter piles often mentioned by engineers are the following: large forces induced onto the pile cap, reduction in bending capacity due to the axial forces, unfavorable rotation on the cap and residual bending moment due to the soil settlement before the earthquake [3]. Several case histories, for example, the wharf failure in the port of Oakland in 1989 during the Loma Prieta earthquake and the port of Los Angeles in 1994 during the Northridge earthquake reveal the unsatisfactory performance of batter piles.

However, recent studies show that batter piles can have a positive performance. As reported by Gazetas and Mylonakis [4], batter piles, if properly designed, can play a beneficial role both for

\footnotetext{
* Corresponding author at: IFSTTAR, GERS, SV, F-44341 Bouguenais, France.

E-mail addresses: lizheng619@hotmail.com, zheng.li@ec-nantes.fr (Z. Li), sandra.escoffier@ifsttar.fr (S. Escoffier),

Panagiotis.Kotronis@ec-nantes.fr (P. Kotronis).
}

the structure they support and the piles themselves (reduction of the bending moments in the piles). Research studies from Pender [5] and Berrill et al. [6] also suggest important beneficial effects from batter piles. The argument about whether the use of batter piles in seismic regions is detrimental or beneficial is therefore still unsettled. In 2004, Harn [7] pointed out that the poor performance of batter piles in past earthquakes may due to the lack of knowledge and analytical tools. Using displacement based design, advanced numerical tools and appropriately detailed batter piles can result in significant project savings.

Several experimental studies on the performance of batter piles in the static domain have already been performed. From 1972 to 1995 Meyerhof and his colleagues conducted experimental campaigns (reduced model scale at $1 \mathrm{~g}$ ) to investigate the bearing capacity of batter piles in soils [8-14]. They proposed an empirical equation to predict the ultimate strength of batter piles under arbitrary load combinations (horizontal and vertical forces). With the development of the centrifuge modeling technique, static tests on batter piles have also been performed on reduced scale models [15-19]. It was observed that batter piles in general increase the horizontal resistance of the foundations.

Centrifuge dynamic tests on batter piles are relatively rare. Escoffier et al. [19] performed centrifuge tests on pile foundations in dry sand by applying a horizontal impact loading on the pile cap with a magnetic hammer. Two pile groups were studied: a $1 \times 2$ (two piles in one row) vertical pile group and a $1 \times 2$ pile group 


\section{Nomenclature}

Roman symbol

SSPSI Seismic Soil-Pile-Superstructure Interaction

$\mathrm{Mj} \quad$ Martinique Jara earthquake (Jara station EW)

$\mathrm{Nr} \quad$ Northridge earthquake (Tarzana station 090)

$\mathrm{Kb} \quad$ Kobe earthquake (DAI8-G, N43W)

C.G. $\quad$ center of gravity of superstructure

IS inclined (batter) pile group with short superstructure 哭

VS

vertical pile group with short superstructure 邑

IT

inclined (batter) pile group with tall superstructure

VT

vertical pile group with tall superstructure $\frac{\pi}{4}$
OM

RBM

$\mathrm{RBM}_{\text {max }}$

$\mathrm{RBM}_{\mathrm{P} 7}$

$\mathrm{RBM}_{\mathrm{P} 7 \text { max,vs }}$ maximum residual bending moment on pile P7 in

vertical pile group with short superstructure

$\mathrm{M} \quad$ total bending moment

$\mathrm{M}_{\mathrm{P7}} \quad$ total bending moment on pile P7

$\mathrm{M}_{\mathrm{P7} \text { max,Vs }}$ maximum total bending moment on pile P7 in vertical pile group with short superstructure

$\mathrm{N}$ axial force in the pile

$\mathrm{N}_{\mathrm{P7}} \quad$ axial force in pile $\mathrm{P7}$

$\mathrm{N}_{\mathrm{P} 7 \text { max, Vs }}$ maximum Axial force in pile P7 in vertical pile group with short superstructure

z depth below ground surface

D external diameter of pile

$\mathrm{D}_{\text {pile }} \quad$ center-to-center distance between piles with one batter pile. Two pile bearing conditions (floating and end bearing) were considered. The tests indicated a more complicated translation-rocking mode for the inclined pile group. Its stiffness was found higher and the resulting movement smaller than that of the vertical pile group. In both groups, the center of rotation of the cap was near the vertical face of the pile cap towards the front pile side. In terms of bending moment profiles, the presence of the batter pile resulted in a decrease of the maximum bending moment below the soil surface in both piles. In addition, the influence of the batter pile on the maximum bending moment at the pile cap interface seemed to be negligible in the front pile, whereas it resulted in an increase of the maximum bending moment in the rear pile. For the batter pile group, the compression load in the front pile and the tension load in the rear pile were increased by a factor of 1.7 and 2.0, respectively.

In 2012, Escoffier [20] performed dynamic centrifuge tests on batter piles. The dynamic loads were applied using an earthquake simulator [21] at the bottom of the model. As in the previous study, two configurations (a $1 \times 2$ vertical pile group and a $1 \times 2$ pile group with one batter pile and end-bearing pile configuration) were studied using earthquake time histories. The results of the seismic tests showed that the batter pile resulted in an increase of the response frequencies corresponding the translation-rotation mode at the pile cap and reduced by two times the maximum horizontal acceleration of the cap. The analysis of the bending moments and axial loads in the piles indicated that with the batter pile, larger residual bending moments were developed and the direction of the axial loads in the piles did not change. Escoffier reported that for batter pile foundations the residual bending moments cannot be ignored in the evaluation of the performance of batter piles.

Okawa et al. [22] performed centrifuge tests on pile groups embedded in loose sand. The first was a $2 \times 4$ pile group composed of 8 vertical piles and the second a $2 \times 4$ pile group with 4 batter piles with an inclination of $10^{\circ}$ and 4 vertical piles. A short superstructure was placed on the footing to study both kinematic interaction and inertial effects. The presence of batter piles decreased the horizontal acceleration amplitude at the footing and the superstructure. Larger axial forces were observed in the batter piles.

Boland et al. $[23,24]$ performed dynamic centrifuge tests with two models (named SMSO2 and JCB01) constructed as a generalization of the pile supported wharf structures common at the Port of Oakland (POOAK), the Port of Los Angeles (POLA) and the Port of Long Beach (POLB) in California. In terms of maximum moments, results clearly showed an increase (from 1.4 to 3.9 times) in recorded pile moments when all vertical piles were used for nearly identical input base accelerations. The shear forces within the batter pile heads were greater (9-20 times) than those recorded in the vertical piles for the same dynamic event. Without batter piles, the shear forces in the vertical piles and the wharf displacements increased significantly [25].

Juran et al. [26] conducted a series of centrifuge tests on vertical and batter micropile groups. The tests showed that with increasing inclination angle the natural frequency of the network system increased. Compared with vertical piles, a reduction of $40 \%$ of the response in terms of acceleration of the superstructure (pile cap) was observed when batter piles were used. In general, increasing the pile inclination resulted in smaller pile cap displacements, and larger axial forces and bending moments in the piles at the pile cap connections.

Giannakou et al. $[27,28]$ studied numerically, in the time domain, the performance of batter piles. Both soil and batter pile groups were modeled using linear elastic constitutive models. Five inclinations were considered. The authors found that for seismic loadings and purely kinematic conditions, the negative reputation (larger bending moments and axial forces) of batter piles was more-or-less confirmed. However, when the total response was considered (kinematic and inertial response of the structural system), their influence can be beneficial. Among the different parameters studied, the performances of batter piles in terms of displacements, bending moments and axial forces depend on the ratio of the overturning moment versus the shear force transmitted to the piles from the superstructure.

Shahrour and Juran [29] performed numerical analysis of the seismic behavior of a micropile system containing batter micropiles. It was found that the inclination of the micropiles allowed an effective mobilisation of their axial resistance, leading to an increase in the stiffness and a reduction in both shear forces and bending moments.

This paper presents a comprehensive experimental seismic centrifuge program on the performance of batter piles in order to better understand their behavior. Several important factors are studied such as Seismic Soil-Pile-Superstructure Interaction 
(SSPSI), the influence of the height of the Gravity Center of the superstructure (C.G.) and of the base shaking signal characteristics. All tests have been performed at $40 \mathrm{~g}$ centrifugal gravity level. Short (squat) and tall (slender) superstructures were used in order to study the influence of the inertial loading from different types of superstructure on the performance of batter piles. A symmetric configuration of batter piles with a $15^{\circ}$ inclination is adopted and results are compared to those of a vertical pile group. For both configurations, rigid connections were imposed at the pile heads through a stiff pile cap. The different behaviors of the two configurations under dynamic excitations are analyzed and discussed.

\section{Experimental set-up}

\subsection{Base shaking signals-selection of real earthquakes}

Two of the main objectives of the experimental campaign are to determine the response frequencies of the soil-pile-superstructure system and to evaluate the performance of batter piles when subjected to multiple-frequencies of base shaking. With this in mind, three different earthquakes were selected. The first two earthquakes are the Northridge (Tarzana station 090) and the Martinique (Jara station EW) records. Both are broad-band frequency range, see Fig. 1(a) and (b). The use of these two earthquakes should enable the determination of the natural frequency of the soil-pile-superstructure system. The third signal is a recording of the Kobe earthquake (DAI8-G, N43W). Most of the energy of this signal comes from frequencies below $2.0 \mathrm{~Hz}$, see Fig. 1 (c), lower than the prior response frequencies of both the soil column and the soil-pile-superstructure system. ${ }^{1}$ In order to be in the capacity range of the shaker [21], these three earthquake signals have been filtered to be within the frequency range of $0.5-$ $8.75 \mathrm{~Hz}(20-350 \mathrm{~Hz}$ at the model scale). According to the different purposes of the tests and the capacity of the shaker [21], earthquake signals are often scaled down, which will be introduced in Section 2.3.

\subsection{Build of the centrifuge models}

The main elements of the physical centrifuge models are the soil deposit with controlled homogeneous density, the piles instrumented with strain gauges, the stiff pile caps and the superstructures. Accelerometers and laser sensors were also installed to record the behavior of the soil-pile-superstructure system.

2.2.1. Properties of the experimental set-up components: sand, piles, pile caps, superstructures and pile groups

The properties and design considerations of each component are introduced hereafter. Dense dry Fontainebleau sand (NE34) was used in all tests and put in place with an air pluviation technique (relative density of about $80 \%$ ). The material properties of Fontainebleau sand are listed in Table 1. The model piles were made of aluminium alloy and had a hollow section. They were instrumented with strain gauges, which enabled the determination of the bending moment profile and the axial stress at different depths. The pile heads were rigidly connected together through stiff pile caps, which induced rotational restraint [30]. The pile caps for both vertical and batter piles were made of two aluminium alloy pieces to ensure an easy assembly with bolts after the sand pluviation. The reason for doing this is to avoid the

\footnotetext{
${ }^{1}$ From previous series of dynamic centrifuge tests, the natural frequencies of the soil column and the soil-pile-superstructure system are about $3.5 \mathrm{~Hz}$ and $2.0 \mathrm{~Hz}$, respectively.
}

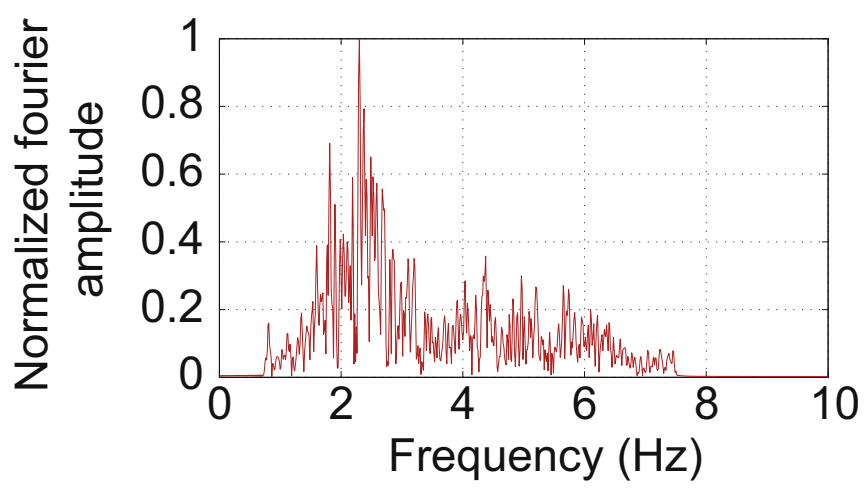

(a)

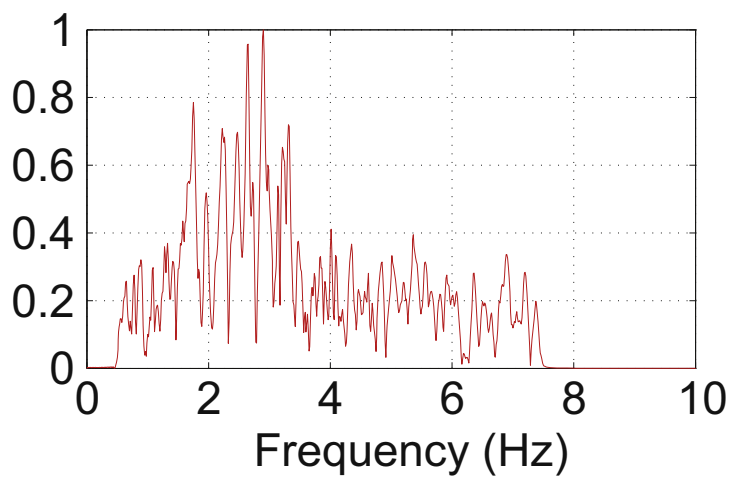

(b)

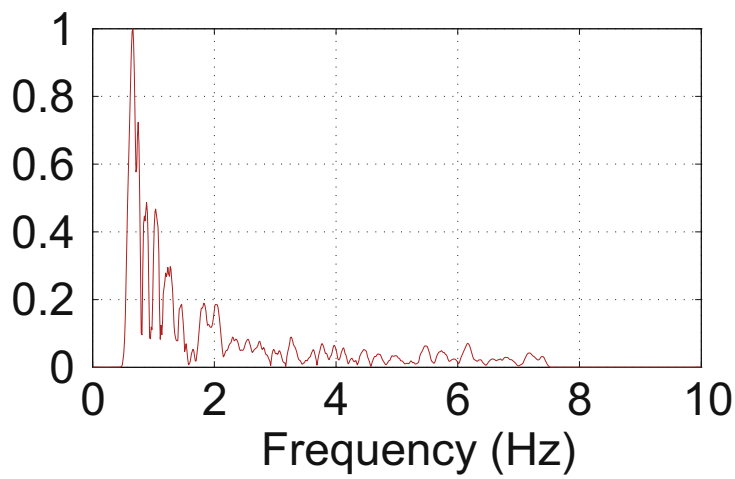

(c)

Fig. 1. Frequency representations (prototype scale) of the base shaking signals: (a) Martinique Jara, (b) Northridge earthquake and (c) Kobe earthquake.

Table 1

Fontainebleau sand NE34: material properties.

\begin{tabular}{lllll}
\hline Soil & $e_{\min }$ & $e_{\max }$ & $\mathrm{e}$ & $D_{r}(\%)$ \\
\hline Fontainebleau NE34 & 0.51 & 0.866 & 0.58 & $80 \%$ \\
\hline
\end{tabular}

Note: $e$ : void ratio; $D_{r}$ : relative density, $D_{r}=\frac{e_{\max }-e}{e_{\max }-e_{\min }}$.

"shadowing effect" of the pile cap during the air pluviation process. Fig. 2 shows the assembly of the batter piles and the pile cap. It can be noticed that the piles were connected with a thin plate before the assembly. Its role was to provide a temporary support to the piles during the sand pluviation process. Table 2 gives the characteristics of the piles and the pile cap in model and prototype scales.

The lateral resistance of the pile cap can significantly increase due to the friction between the soil and the cap, especially when the pile cap is embedded beneath the ground surface, [31-34]. In 

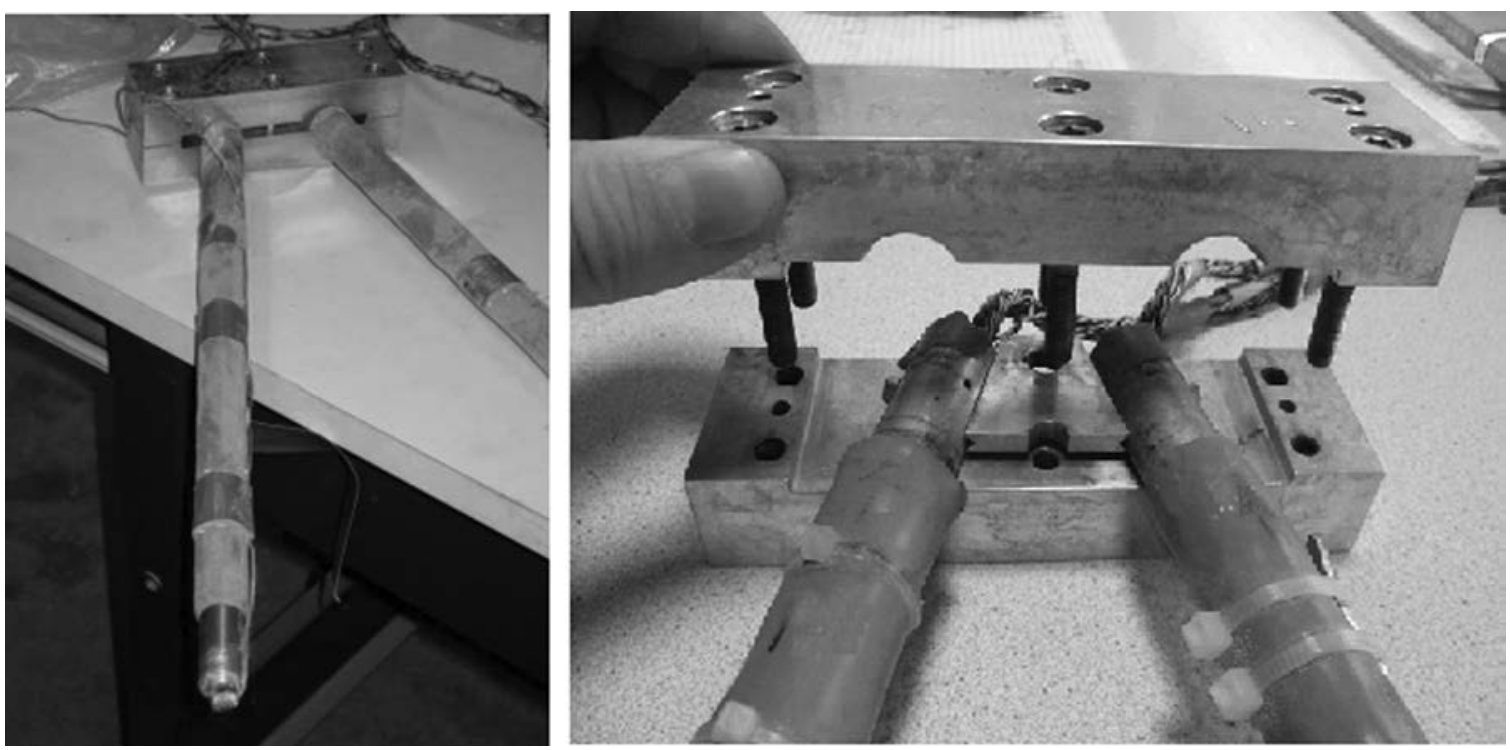

Fig. 2. Assembly of batter piles and pile cap pieces.

Table 2

Characteristics of the piles and of the pile cap.

\begin{tabular}{lll}
\hline Item & Model scale $40 \mathrm{~g}$ & Prototype scale $1 \mathrm{~g}$ \\
\hline Pile-embedded depth & $326.5 \mathrm{~mm}$ & $13.06 \mathrm{~m}$ \\
Pile-external diameter & $18 \mathrm{~mm}$ & $0.72 \mathrm{~m}$ \\
Pile-bending stiffness & $197 \mathrm{~N} \mathrm{~m}^{2}$ & $505 \mathrm{MN} \mathrm{m}$ \\
Pile-yield strength & $245 \mathrm{MPa}$ & $245 \mathrm{MPa}$ \\
Pile cap-dimensions & $140 \mathrm{~mm} \times 40 \mathrm{~mm} \times 40 \mathrm{~mm}$ & $5.6 \mathrm{~m} \times 1.6 \mathrm{~m} \times 1.6 \mathrm{~m}$ \\
Cap-weight & $5.5 \mathrm{~N}$ & $331.24 \mathrm{kN}$ \\
\hline
\end{tabular}

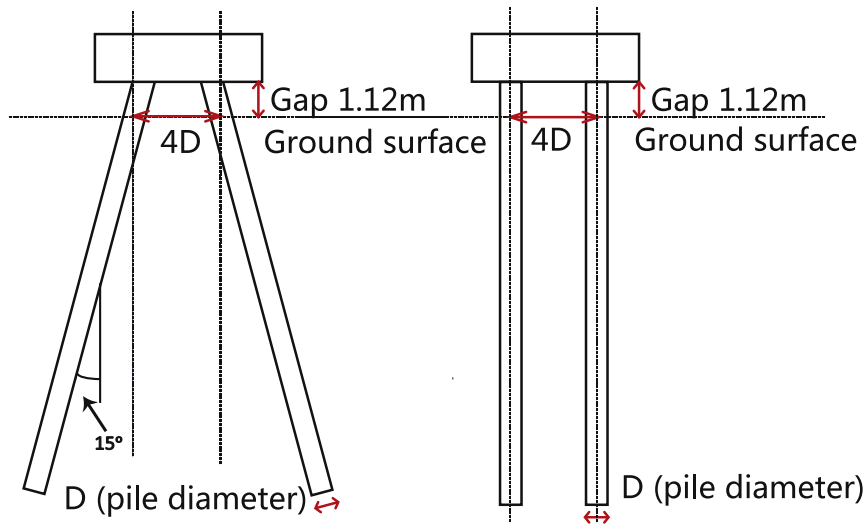

Fig. 3. Geometrical characteristics of the batter pile and the vertical pile groups (prototype scale).

order to avoid soil-cap interaction, the piles were designed to stand at a certain distance above the ground surface, see Fig. 3. The gap between the pile cap and the ground surface is $28 \mathrm{~mm}$ at model scale (1.12 $\mathrm{m}$ at prototype scale). The spacing of the piles, i.e. the center-to-center distance between the piles, was 4 times the diameter of the piles ( $4 D$ ) for both pile group configurations. Floating pile group configurations were considered. In order to study the influence of the height of the Gravity Center of the superstructure (C.G.) on the responses of the pile foundations, two types of single degree of freedom superstructures were used, i.e. a short and a tall superstructure. Both superstructures were designed to have:

- the same resonant frequency under fixed base conditions,

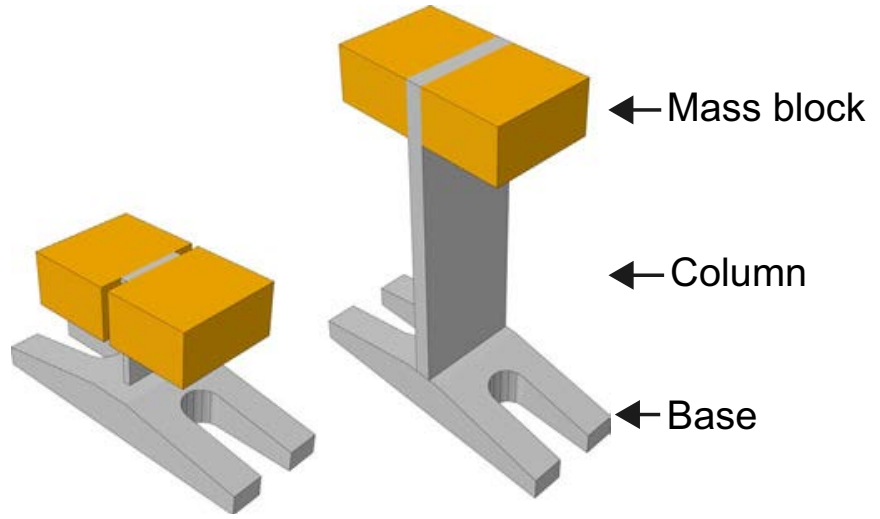

Fig. 4. Short and tall superstructures used in the experiments.

- the same top mass weight,

- the same total weight of the whole foundation-superstructure system.

Fig. 4 shows the two superstructures. They were made of three parts: the top mass, the supporting column and the base. The top mass was made from brass, the column and the base from aluminium alloy. The base was designed in a way to provide a fixed connection with the superstructure. After the superstructure installation, the base together with the pile cap constituted an enlarged new foundation, Fig. 5. The frequency of the fixed-based building was designed to be $2.0 \mathrm{~Hz}$. Due to the $1.12 \mathrm{~m}$ distance between the pile cap and the soil surface, after the installation of superstructure, the height or the gravity center of the top mass was thus increased. The foundation superstructure system can be idealized using lumped masses, see Fig. 5. Since the column supporting the building cannot be regarded as weightless, according to Harris and Piersol [35], approximately $23 \%$ of the mass of the column should be included in the top mass while the rest $77 \%$ goes to the base. The gravity center of the pile foundation, $H_{c a p}$, is $1.92 \mathrm{~m}$ (including the gap between the pile cap and the soil surface); the gravity center $H_{\text {mass }}$ of the building was measured from the ground surface. The detailed characteristics of the pile foundations with short and tall superstructures are listed in Table 3. 


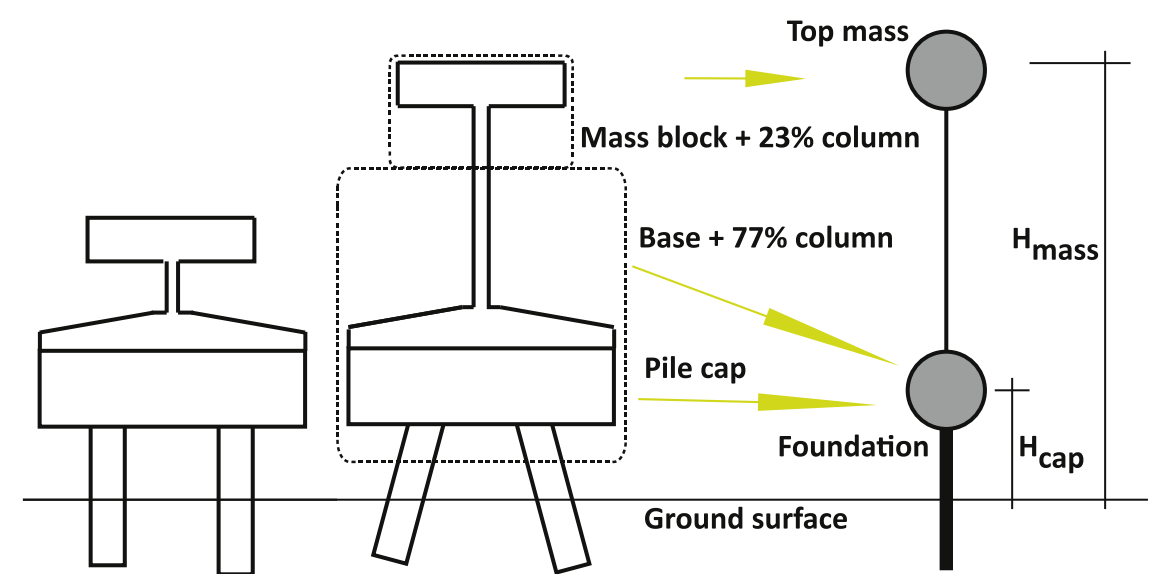

Fig. 5. Foundation-superstructure discretization.

Table 3

Main characteristics of the pile foundations with short and tall superstructures.

\begin{tabular}{|c|c|c|c|c|}
\hline & \multicolumn{2}{|l|}{ Short } & \multicolumn{2}{|l|}{ Tall } \\
\hline & $\begin{array}{l}\text { Model scale } \\
40 \mathrm{~g}\end{array}$ & Prototype $1 \mathrm{~g}$ & $\begin{array}{l}\text { Model scale } \\
40 \mathrm{~g}\end{array}$ & Prototype $1 \mathrm{~g}$ \\
\hline Top mass weight & $0.85 \mathrm{~kg}$ & 54.40 tonne & $0.84 \mathrm{~kg}$ & 53.67 tonne \\
\hline $\begin{array}{l}\text { Foundation mass } \\
\text { weight }\end{array}$ & $0.20 \mathrm{~kg}$ & 12.80 tonne & $0.34 \mathrm{~kg}$ & 21.85 tonne \\
\hline Total weight & $1.05 \mathrm{~kg}$ & 67.20 tonne & $1.18 \mathrm{~kg}$ & 75.52 tonne \\
\hline $\begin{array}{l}\text { Height of C.G. } \\
H_{\text {mass }}\end{array}$ & $128.0 \mathrm{~mm}$ & $5.12 \mathrm{~m}$ & $211.0 \mathrm{~mm}$ & $8.48 \mathrm{~m}$ \\
\hline $\begin{array}{l}\text { Height of C.G. } \\
\quad H_{\text {cap }}\end{array}$ & $48.0 \mathrm{~mm}$ & $1.92 \mathrm{~m}$ & $48.0 \mathrm{~mm}$ & $1.92 \mathrm{~m}$ \\
\hline $\begin{array}{l}\text { Frequency of } \\
\text { building }\end{array}$ & $81.0 \mathrm{~Hz}$ & $2.03 \mathrm{~Hz}$ & $80.4 \mathrm{~Hz}$ & $2.01 \mathrm{~Hz}$ \\
\hline
\end{tabular}

\subsubsection{Experimental procedure: preparing the sand-pile system}

Fontainebleau sand with $80 \%$ relative density was used for the soil pile system. The homogeneity of the sand deposit was controlled with the air pluviation technique. In centrifuge tests, the methods to install the piles are different from the engineering practice (where batter piles are installed into the soil by driving). Escoffier et al. [19] discussed the influences of the different ways of pile installation on the final response.

The following method was adopted in this experimental study. First, all piles were fixed and maintained to their precise positions in the Equivalent Shear Beam (ESB) container [36,37] at $1 \mathrm{~g}$. Vertical shear rods were attached to the bottom of the container to provide complimentary shear stresses, see Fig. 6 . Then the sand was filled by air pluviation from the bottom up to the level of the ground surface. A temporary sustaining system was used to maintain the pile group during pluviation, composed of an aluminium plate, ${ }^{2}$ two steel rods and thin plastic wires, ${ }^{3}$ see Fig. 6. All pieces in the temporary supporting system had to be thin enough to minimize the "shadowing effect" during sand pluviation. ${ }^{4}$ After pluviation, the pile cap was installed onto the pile head by tightening the bolts with a dynamic torque screwdriver. Finally, the superstructure was installed onto the top of the pile cap.

Sensors were installed to record the movement of the soil-pile-

\footnotetext{
${ }^{2}$ The thin aluminium plate was used to maintain the inclination angle of $15^{\circ}$.

3 The steel rods and the plastic wire were used to minimize the impact on the piles. When the sand surface was about $5 \mathrm{~cm}$ higher than the tips of the piles, the wires were cut to free the pile tips. After the sand surface arrived at the prescribed height, the pluviation stopped and the steel rods were removed.

${ }^{4}$ Shadowing effect: during sand pluviation the presence of items can influence the falling of sand into the container and thus affect the homogeneity of the sand deposit.
}

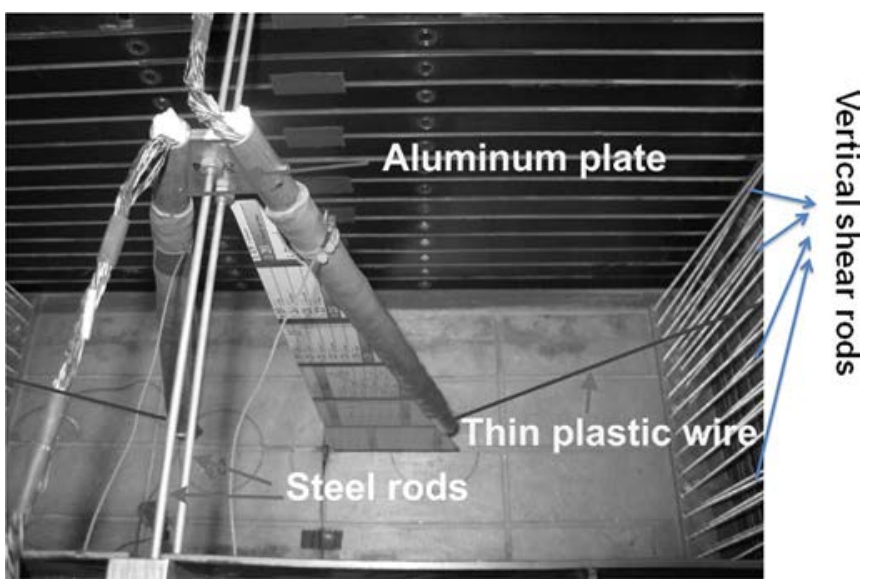

Fig. 6. Position of the piles in the ESB container.

superstructure system. Their configuration (arrangement) in the centrifuge model is shown in Fig. 7. The acceleration of the soil column was tracked by a vertical array of accelerometers, $\mathrm{CH03} \mathrm{CH09}$, which located away from the piles. Comparison of the measured maximum accelerations and displacements with those from the free field tests ${ }^{5}$ showed that these measured accelerations are representative of the free field condition and were not influenced by the pile group. The movements of the pile cap and of the superstructure were monitored by accelerometers $\mathrm{CH} 10 \sim \mathrm{CH} 13$. Furthermore, three high speed laser sensors were used on the superstructure. Several accelerometers were attached on one side of the container in order to capture the response of the container.

\subsection{Experimental procedure: program and test repeatability}

For each pile foundation superstructure configuration, 18 earthquake inputs were used, see Table 4. The Arias intensities [38] are shown in Fig. 8. The first two small earthquakes were used to estimate the frequency response of the soil-pile-superstructure system. The last two small earthquakes were used to study the dynamic responses of the different pile configurations after extreme earthquake events. In order to verify the repeatability of the experimental results, some tests were performed twice. Fig. 9 provides an example of the results for two identical tests performed on the batter pile group with tall superstructure. Results indicate a good repeatability.

\footnotetext{
${ }^{5}$ The free field tests were performed previously.
} 


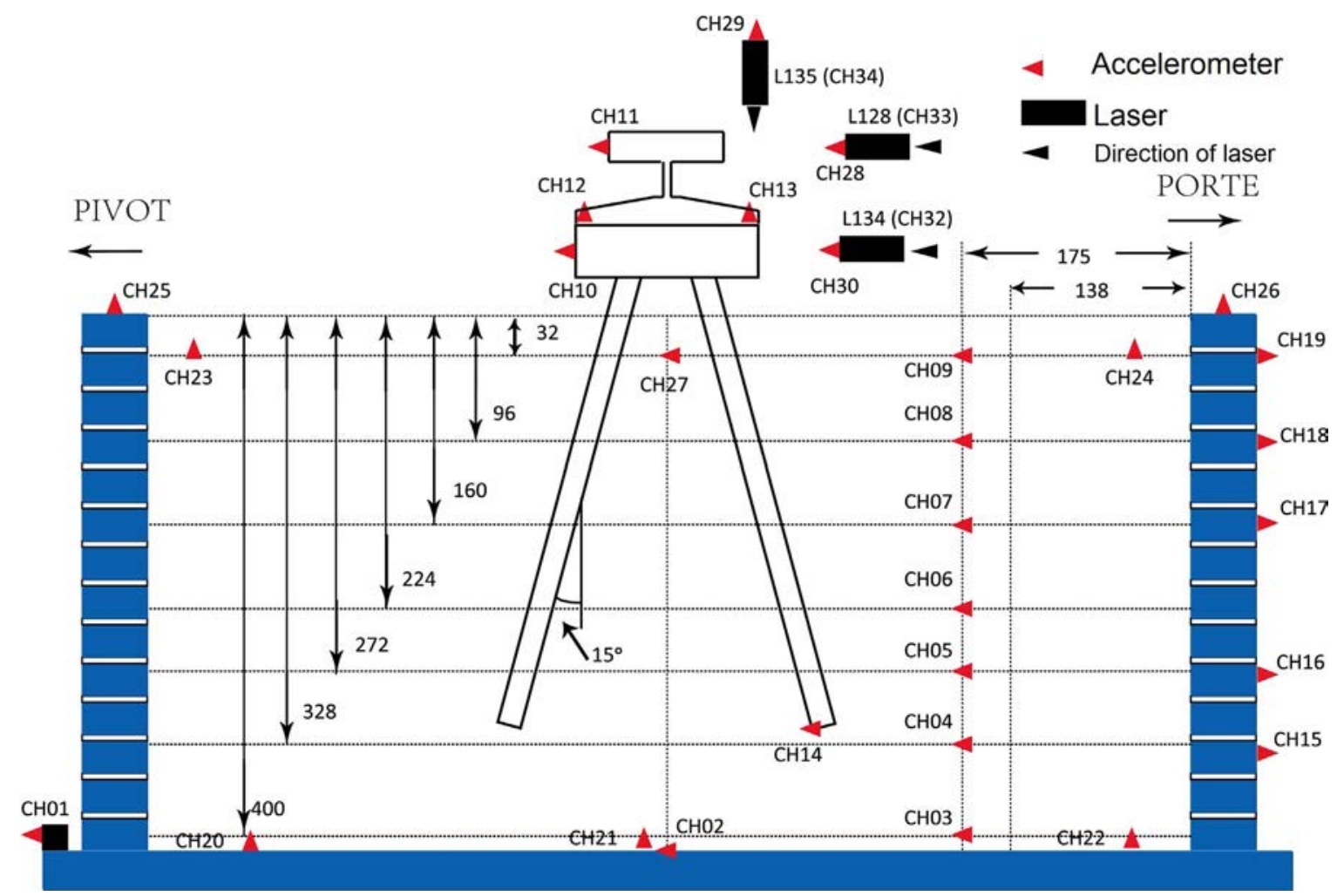

Fig. 7. Configuration of the sensors in the centrifuge tests (at model scale in $\mathrm{mm}$ ).

Table 4

Applied sequences of the real earthquake signals.

\begin{tabular}{|c|c|c|c|c|c|}
\hline No. & Excitations & Seismic signal & Attenuation (dB) & $\mathrm{PGA}\left(\mathrm{m} / \mathrm{s}^{2}\right)$ & Arias intensity $(\mathrm{m} / \mathrm{s})$ \\
\hline Test 1 & $1,2,3$ & Martinique Jara & -1 & 0.9 & 0.2 \\
\hline Test 2 & $4,5,6$ & Northridge & -20 & 1.35 & 0.2 \\
\hline Test 3 & $7,8,9$ & Northridge & -9 & 4.79 & 2.43 \\
\hline Test 4 & $10,11,12$ & Kobe & -4 & 3.83 & 3.51 \\
\hline Test 5 & $13,14,15$ & Martinique Jara & -1 & 0.9 & 0.2 \\
\hline Test 6 & $16,17,18$ & Northridge & -20 & 1.35 & 0.2 \\
\hline
\end{tabular}

Note:

1. Martinique Jara earthquake is abbreviated to Mj; Northridge earthquake is abbreviated to Nr; Kobe earthquake is abbreviated to Kb.

2. Values of PGA (peak ground acceleration) and Arias Intensity are in prototype.

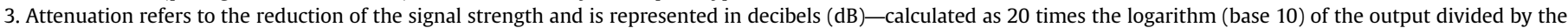
input.

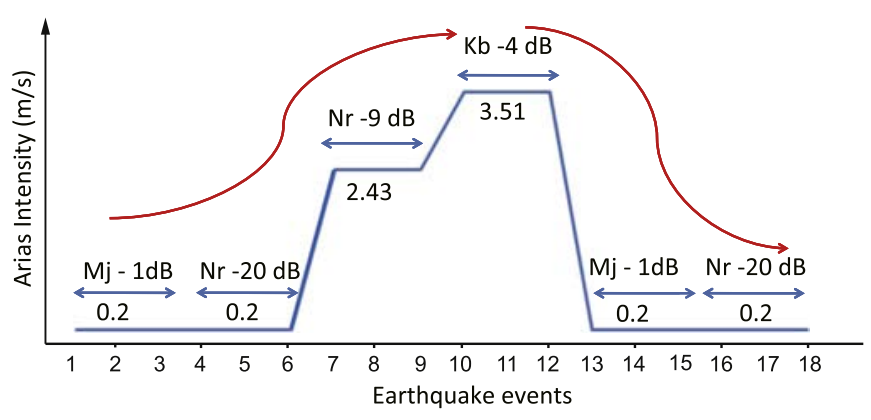

Fig. 8. Arias intensities.

\section{Definitions, assumptions}

Several definitions and assumptions concerning the analysis and interpretation of the experimental results are introduced in this section.

\subsection{Pile names definition}

In the dynamic centrifuge tests, there is no front or rear pile as the sign of the loading changes. Piles are named hereafter P7 and P8 refering to their positions: the pile close to the "Porte", on the right-hand-side, is called P7 and the pile close to the "Pivot", P8 see Fig. 10.

\subsection{Residual, dynamic and total bending moment}

During an earthquake event, due to permanent soil deformations and the influence of the superstructure, embedded pile foundations may move from their initial position. Permanent lateral displacements may occur at the pile head and along the pile, see Fig. 11. The residual bending moment is defined as the difference between the bending moment at the beginning and at the end of the earthquake event, see Fig. 12. As shown in the same figure, the total bending moment can be decomposed into two parts: a dynamic and a residual part. 


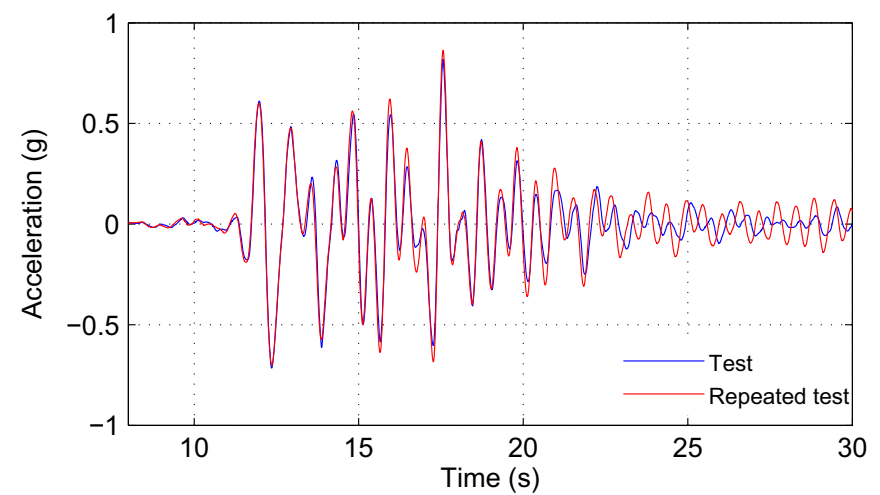

(a)

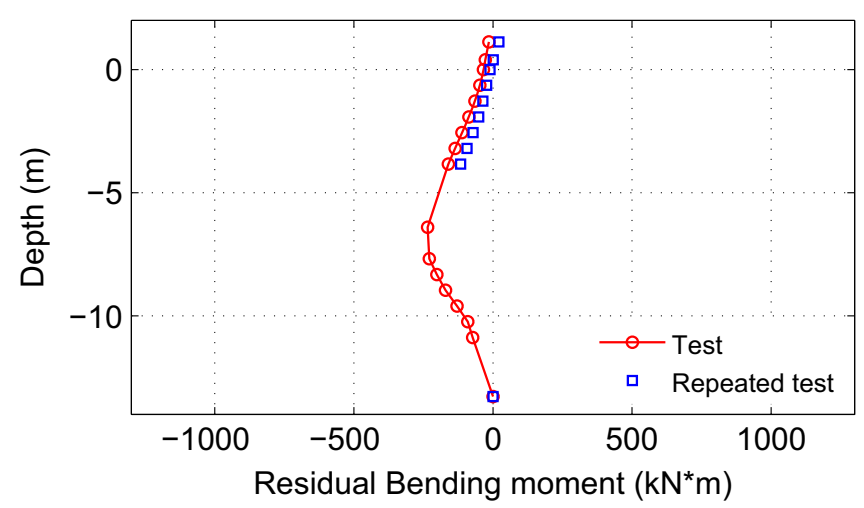

(b)

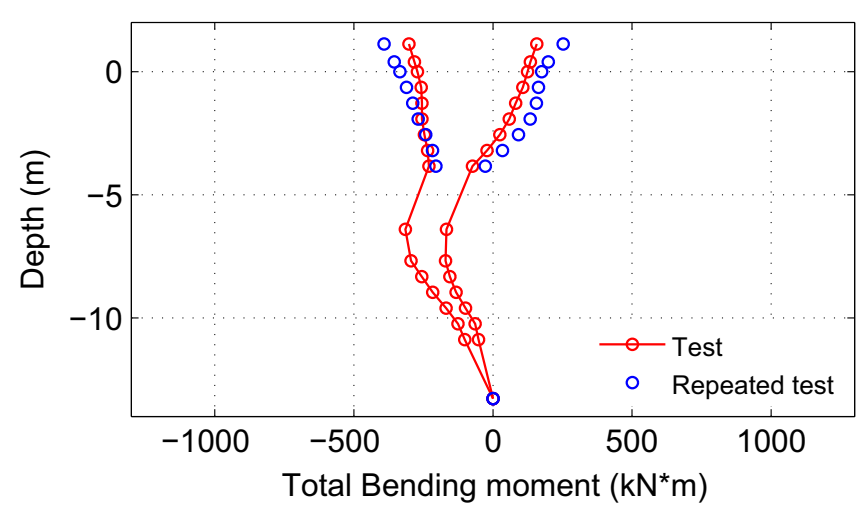

(c)

Fig. 9. Results of the 12 th Kobe $-4 \mathrm{~dB}$ strong earthquake, batter piles with tall superstructure (prototype scale): (a) responses of the top mass; (b) residual bending moment and (c) total bending moment.

\subsection{Accumulation effect}

It was observed during the tests that successive earthquake events influence the residual bending moment. However, if the same earthquake signal is applied 3 times, the evolution or the "accumulation" effect is found limited. Furthermore, the last small earthquakes do not induce new residual bending moments. Fig. 13 shows for example the evolution of the residual bending moment of the batter pile group with tall superstructure under different earthquake events.

\subsection{Rotation (rocking) and horizontal displacement (translation) of the pile cap}

In the experiments, the responses of the pile cap and the

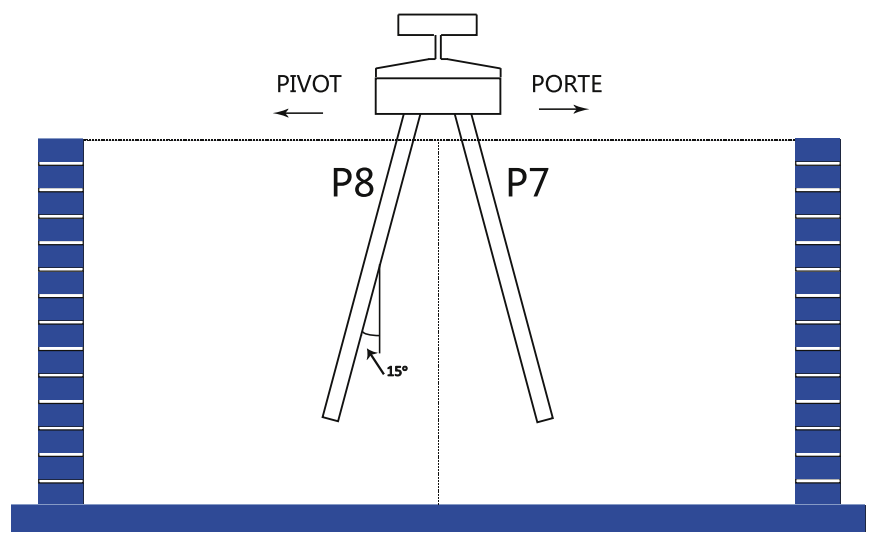

(a) Batter (inclined) pile group

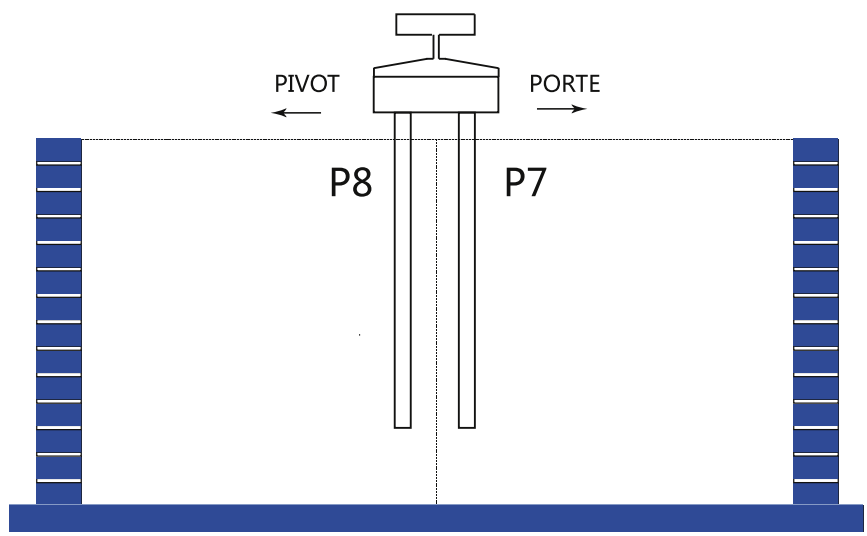

(b) Vertical pile group

Fig. 10. P7 and P8 piles in the batter and vertical pile groups.

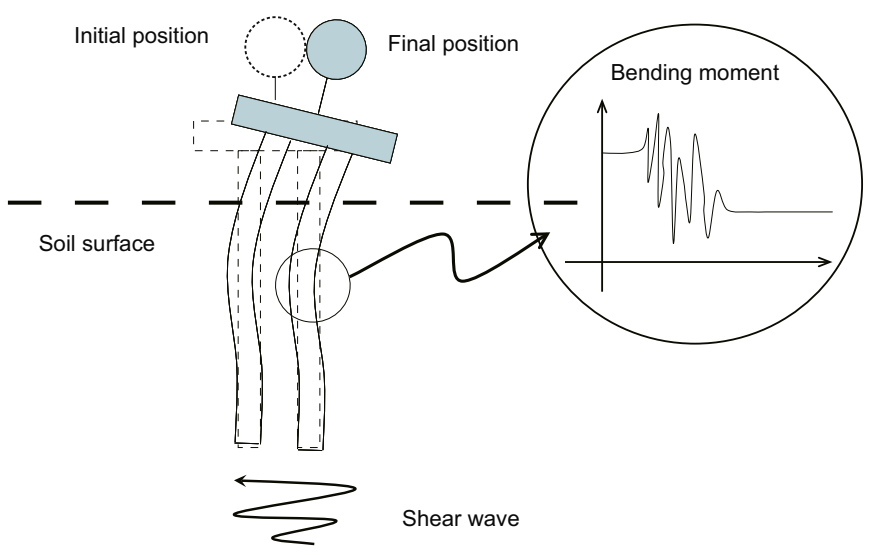

Fig. 11. Residual lateral displacements.

superstructure are monitored by sets of accelerometers as shown in Fig. 14. The vertical accelerations of the pile cap are recorded by the sensors $\mathrm{CH} 12$ and $\mathrm{CH} 13$. The horizontal accelerations of the pile cap and the superstructure are measured by the sensors $\mathrm{CH} 10$ and $\mathrm{CH} 11$, respectively. The sensor $\mathrm{CHO9}$ is far enough away from the pile foundation and it is used to capture the acceleration near the soil surface. The rotation of the pile cap can be derived from $\mathrm{CH} 12$ and $\mathrm{CH} 13$. The relative translation of the pile cap with respect to the soil surface is obtained by calculating the difference between the displacement of the pile cap and the displacement of the soil surface. The displacement time histories are obtained by double integration [39] of the measured acceleration time histories, the accuracy of the double integration is validated [40] by 


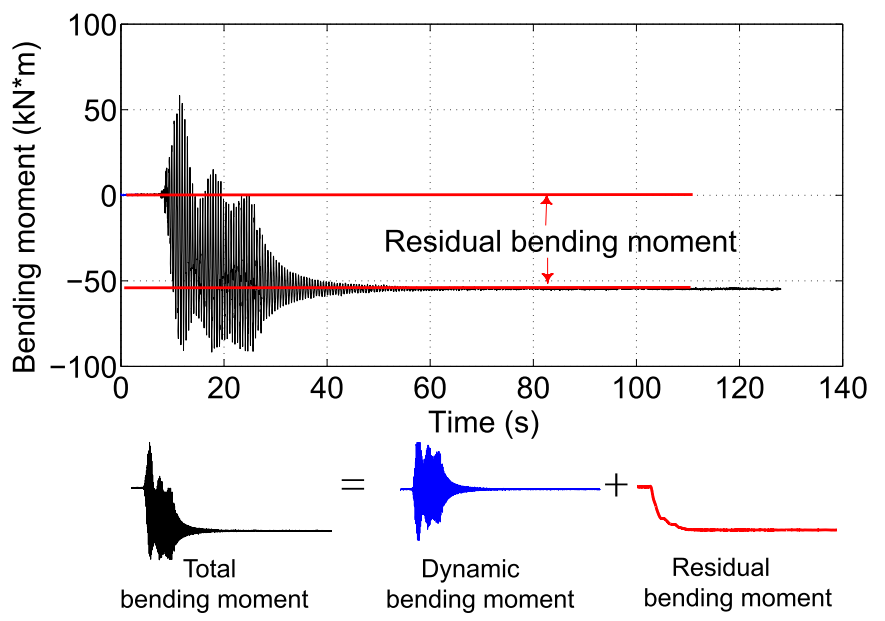

Fig. 12. Total, dynamic and residual bending moments.

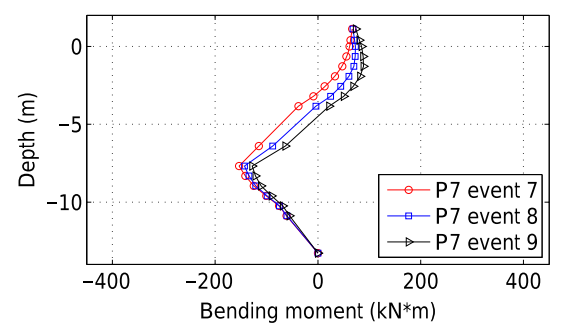

(a)

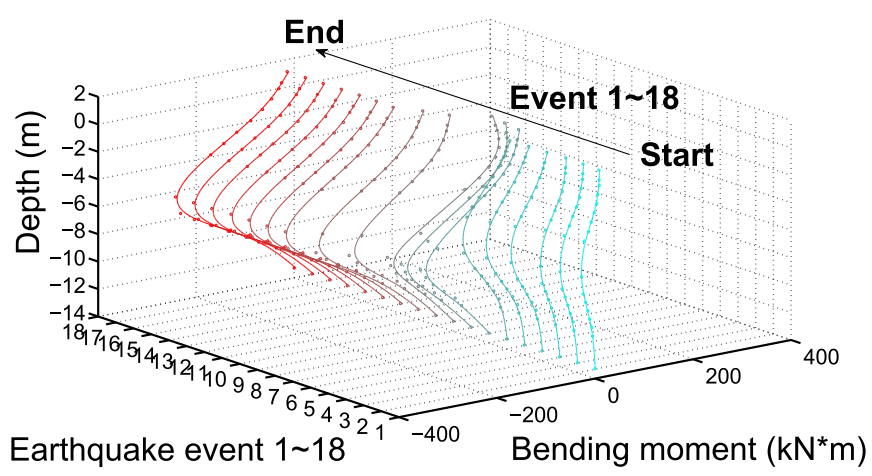

(b)

Fig. 13. Accumulation of residual bending moment-batter pile group with tall superstructure (results of $\mathrm{P7}$, prototype scale): (a) residual bending moment under the Northridge $-9 \mathrm{~dB}$ earthquake, events 7, 8 and 9; and (b) evolution of the residual bending moment during all the 18 earthquake events.

the laser sensors (L128, L134 and L135) ${ }^{6}$ installed near the superstructure, see Fig. 7. Due to the frequency range of the accelerometers, the residual part of the rotations and the displacements cannot be monitored. Therefore, the displacements and rotations calculated from the measured accelerations represent only the dynamic components.

\subsection{Overturning moment and total horizontal force (base shear)}

The overturning moment (OM) and the base shear force (BS) are calculated from the inertia forces generated by the mass of the superstructure and the base using Eqs. (1) and (2).

\footnotetext{
${ }^{6}$ In the tests, laser sensors only measured the absolute displacements of the superstructure and it is difficult to determine the relative displacements of the superstructure with respect to ground surface. Therefore, the relative displacements of the superstructure with respect to ground surface are determined by pair of accelerometers.
}

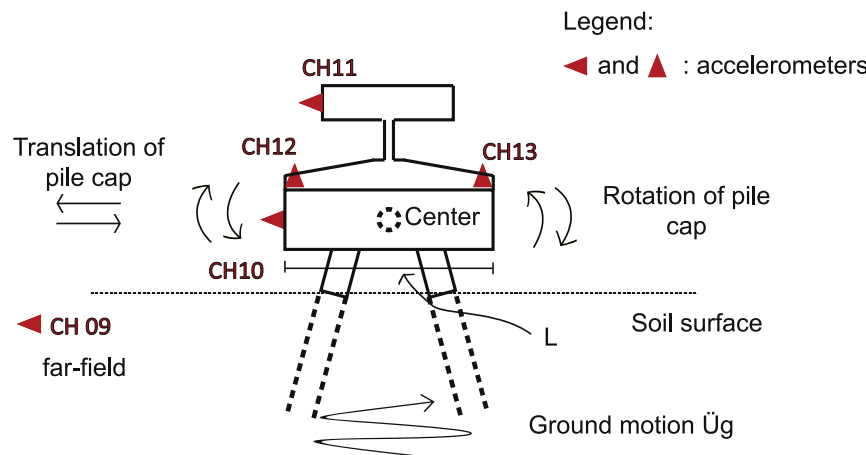

Fig. 14. Illustration of the response of the pile cap.

$\mathrm{OM}=M_{\text {mass }} \ddot{u}_{\text {mass }} H_{\text {mass }}+M_{\text {cap }} \ddot{u}_{\text {cap }} H_{\text {cap }}$

$\mathrm{BS}=M_{\text {mass }} \ddot{u}_{\text {mass }}+M_{\text {cap }} \ddot{u}_{\text {cap }}$

where $M_{\text {mass }}$ and $M_{\text {cap }}$ are the masses, $H_{\text {mass }}$ and $H_{\text {cap }}$ the C.G. and $\ddot{u}_{\text {mass }}$ and $\ddot{u}_{\text {cap }}$ the measured accelerations at the top mass and at the pile cap, respectively. The overturning moments and horizontal forces are calculated only from the measured horizontal accelerations, no other forces are considered.

\subsection{Representative values}

According to Table 4, each earthquake was applied 3 times. Nevertheless, it was observed that experimental data (such as acceleration, bending moment and axial force) recorded from the 3 successive identical inputs were similar, see Fig. 15 for example. This may due to the high density of the sand used in the experiments that limits the evolution of the behavior of the soil-pilefoundation system. The maximum values obtained during the three same earthquake events are chosen as the representative values (conservative approach).

From the experimental results it was also found that for both batter and vertical piles, bending moments (residual and total) and axial forces measured in pile P7 are higher than (or equal to) those measured in P8 (this is may due to the first loading direction). The maximum response in pile $\mathrm{P7}$ is therefore considered as the representative value.

\subsection{Data normalization-interpretation of the results}

In order to evaluate the performance of the batter piles and the influence of the superstructures they support, cross comparisons were made between the different configurations. The percentage of increase $(P>0 \%)$ or decrease $(P<0 \%)$ of a measured quantity due to the use of batter piles is calculated using Eq. (3).

$P=\frac{Q_{\max , I}-Q_{\max , V}}{Q_{\max , V}}$ in (\%)

where $P$ is the performance index of the batter piles, $Q_{\max , I}$ and $Q_{\max , V}$ the measured quantities on the batter and vertical pile configurations, respectively. In this way, results obtained on one configuration (batter pile group with tall or short building) are normalized with respect to the corresponding vertical pile group with the same superstructure. Coloured bars are used to represent the performance index $P$, see for example Fig. 16. A positive value corresponds to a negative behavior of the batter pile (symbol $\ominus$ ) compared to the vertical one; the symbol $\oplus$ indicates a beneficial behavior. In addition, maximum values obtained for the vertical pile groups are indicated on the top of the figure. In Fig. 16 for 


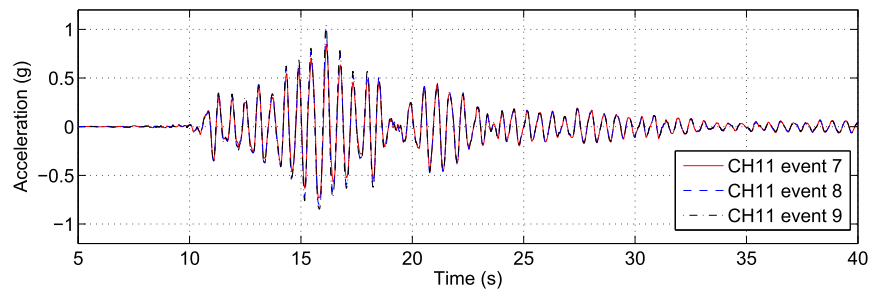

(a)

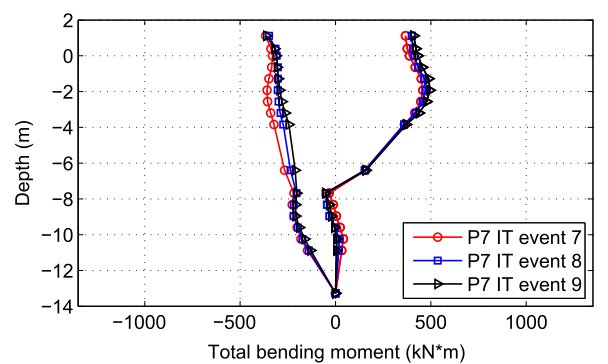

(b)

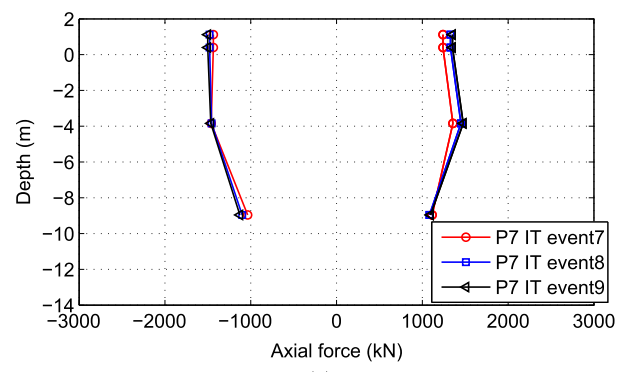

(c)

Fig. 15. Results of the $\mathrm{Nr}-4 \mathrm{~dB}$ strong earthquake, batter piles with tall superstructure, events 7, 8 and 9 (results of P7, prototype scale): (a) acceleration history at the top of superstructure (b) total bending moment and (c) axial force.

example, batter piles have a negative effect especially when they support a tall superstructure. Another different normalization rule is adopted for the stress profiles in the piles. Among all the pile configurations, the vertical piles with the short superstructure (VS) is selected as the reference configuration. The stress profiles are thus all normalized with respect to the maximum value recorded on the referenced configuration. The maximum value on the reference configuration is chosen regardless the location where it appears along the pile (either at pile head or other locations).

\subsection{Zero initial stress state}

In the tests, for both vertical and batter piles, the possible initial pile stresses (bending moments and axial forces) generated during the air pluviation, the assembling of the pile cap and the spinning up of the centrifuge were not measured. Therefore, the analysis of the performance of the batter piles is based on the assumption that the initial pile stresses are zero. Furthermore, since both the short and tall superstructures are designed to have approximately the same total weight, the initial states for all pile configurations are assumed identical. Although the inclination of piles may induce differences, this effect is not taken into account.

\section{Performance of batter piles considering Seismic Soil-Pile- Superstructure Interaction (SSPSI)}

In this part, the results are presented at the prototype scale unless otherwise mentioned. It has been checked that the performance of the container did not influence the frequency of the ground motions (almost the same frequency response of the container and the soil column).

Under seismic loading, piles that support superstructure are subjected not only to the kinematic interaction but also to inertia interaction. The inertial loads coming from the superstructure can significantly influence the behavior of the pile foundations [28]. In return, the behavior of the superstructure is influenced by the movement of the piles (Seismic Soil-Pile-Superstructure Interaction (SSPSI)). The following section provides the main results of the experimental campaign focused on the behavior of batter and vertical piles under SSPSI and put in evidence, among others, the significant influence of the superstructure and the characteristics of the base shaking signal on the performances of both batter and vertical piles.

\subsection{Frequencies}

The first two small earthquakes ( 6 base shaking events) were used to evaluate the frequency response of the different pile group configurations (IS: batter (inclined) - small building, VT: vertical tall building etc., see Table 5). For this, transfer functions are calculated from the accelerations measured on the top of the superstructure ( $\mathrm{CH} 11)$ or at the pile cap ( $\mathrm{CH} 10)$ and those measured near the soil surface ( $\mathrm{CH} 09$ ). The estimated corresponding frequencies are listed in Table 5. For all cases, soil-structure interaction decreases the superstructure's natural frequency when comparing with fixed-based conditions $(2.0 \mathrm{~Hz})$. The percentage of decrease for configuration IS, VS, IT and VT are $-3 \%,-10 \%-15 \%$ and $-19 \%$, respectively.

The presence of batter piles reduces the effect of SSPSI on the frequencies, especially for the configuration with a short building. This is due to the fact that batter piles contribute to a higher horizontal stiffness. For the case of short and tall superstructures installed on batter piles, frequencies are $0.14 \mathrm{~Hz}$ and $0.08 \mathrm{~Hz}$

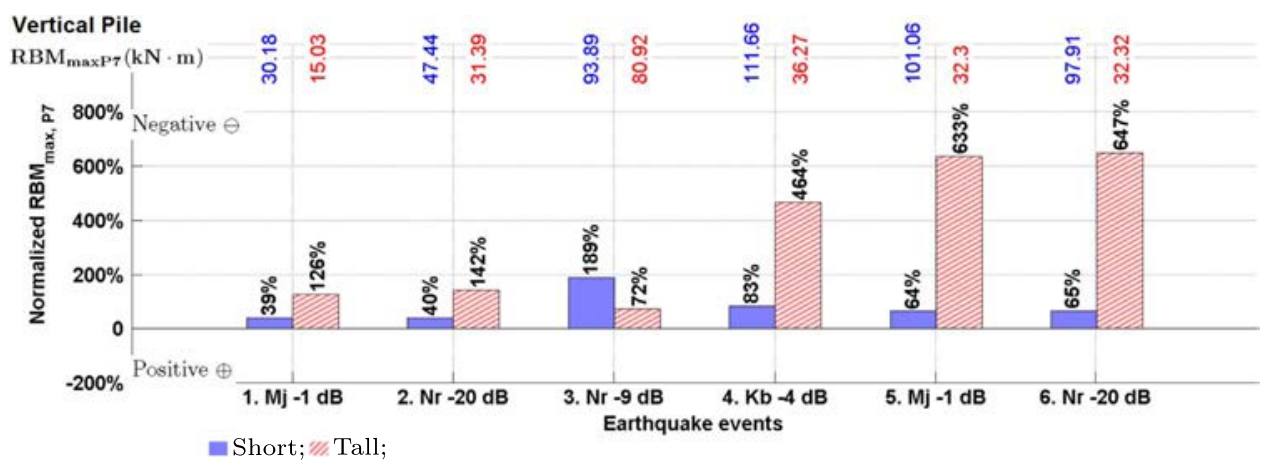

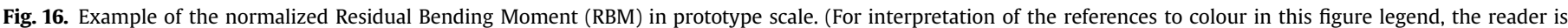
referred to the web version of this article.) 
Table 5

Frequencies of the different pile configurations.

\begin{tabular}{lll}
\hline Configurations & $\begin{array}{l}\text { Natural frequency of the super- } \\
\text { structure }(\mathrm{Hz}) \\
\text { (calculated by } \frac{\mathrm{CH} 11}{\mathrm{CH}} \text { ) }\end{array}$ & $\begin{array}{l}\text { Natural frequency of the } \\
\text { pile cap }(\mathrm{Hz}) \\
\text { (calculated by } \frac{\mathrm{CH} 10}{\mathrm{CH}} \text { ) }\end{array}$ \\
\hline IS & 1.94 & 6.28 \\
VS & 1.80 & 4.26 \\
VT
\end{tabular}

higher than for the vertical pile groups. An increase of the height of C.G. decreases the frequency response of the superstructure for both pile group configurations $(-0.24 \mathrm{~Hz}$ and $-0.18 \mathrm{~Hz}$ for the batter and the vertical pile group, respectively). This effect is more pronounced for the batter pile configuration.

The presence of a superstructure modifies also the response of the pile cap. Previous tests without superstructures have shown that the frequencies of the batter and vertical pile groups are 10.6 $\mathrm{Hz}$ and $6.0 \mathrm{~Hz}$, respectively. When introducing a short or a tall superstructure with similar rigid base frequency on batter piles, the frequency of the pile cap is found decreased (from $10.6 \mathrm{~Hz}$ to $6.28 \mathrm{~Hz}$ and from $10.6 \mathrm{~Hz}$ to $7.12 \mathrm{~Hz}$, respectively).

\subsection{Displacements and rotations of the pile cap}

The maximum displacements and rotations of the pile cap are shown in Figs. 17 and 18, respectively. The pile cap movement is crucial as it is often used in design criteria. Looking at the pile cap maximum horizontal displacements, batter piles play a beneficial role both for short and tall superstructures. These results are in accordance with previous results $[26,28,27]$. This performance is influenced by the characteristics of the base shaking signal and the height of the superstructure. However, these tests show that the beneficial influence is more pronounced for the short superstructure (30-50\%) than for the tall one (8-34\%), except for the $\mathrm{Kb}$ $-4 \mathrm{~dB}$ earthquake (whose frequency content is below the frequency responses of the total system (soil, piles, superstructure)). Giannakou et al. $[27,28]$ pointed out that the performance of batter pile depends on the ratio of the overturning moment versus the shear force transmitted to the piles from the superstructure. In terms of pile cap displacement, the beneficial role of batter piles is more highlighted for the case of short superstructure with small ratio of overturning moment (OM) to base shear (BS). The ratios of overturning moment to base shear for different configurations are summarized in Table 6. It can be concluded from the experimental results that short superstructure has small ratio of overturning moment to base shear which is shear force dominant; and tall superstructure has overturning moment dominant inertial force with larger ratio of overturning moment to base shear, see Table 6 .

In terms of maximum rotations (Fig. 18), the performance of the batter piles is influenced by the base shaking characteristics (frequency content and amplitude) and the type of the superstructure. For small earthquakes, batter piles induce a higher rotation at the pile cap level. This effect is more pronounced for the configurations with a tall superstructure (except for the last small Northridge event). This result is in accordance with the conclusions of Giannakou [27] from linear elastic finite element simulations. This may due to the shear interface stiffness along batter piles is less than the vertical pile cap rotational stiffness. For stronger earthquakes however, batter piles have almost no effect for the case of a tall superstructure or only a slightly beneficial role when a short superstructure is supported. This effect may due to the more important nonlinear behavior of the soil developed during strong earthquakes.

\subsection{Total base shear}

The normalized maximum total base shear forces for all the different configurations and earthquake events are shown in Fig. 19. For a short superstructure, batter piles play a beneficial role as they reduce the maximum total base shear. Again, this beneficial role depends however on the frequency content and the amplitude of the base shaking signal. In particular for strong earthquakes, the reduction is less pronounced $(-35 \%$ for the small Northridge earthquake against $-20 \%$ for the large Northridge earthquake). For a tall superstructure, the use of batter piles can be detrimental or beneficial depending on the frequency of the earthquake and its amplitude. Its beneficial influence is more important for strong earthquakes. In general, the positive role of batter piles is more pronounced for the case of a short superstructure with small ratio (about 3-5, see Table 6) of OM/BS (except for the 4 th $\mathrm{Kb}$ earthquake).

\subsection{Total overturning moment}

Results are summarized in Fig. 20. Batter piles play a beneficial role as they reduce the maximum total overturning moments ( -11 to $-55 \%)$. As before, this beneficial role seems more pronounced for the case of a short superstructure with small ratio of $\mathrm{OM} / \mathrm{BS}$. The reduction is -14 to $-55 \%$ when short superstructure is supported against -11 to $-25 \%$ for a tall superstructure (except for the 4 th $\mathrm{Kb}$ earthquake).

\subsection{Stresses in piles}

In this section, the "generalized" stresses along the piles (bending moments and axial forces) resulting from the combined

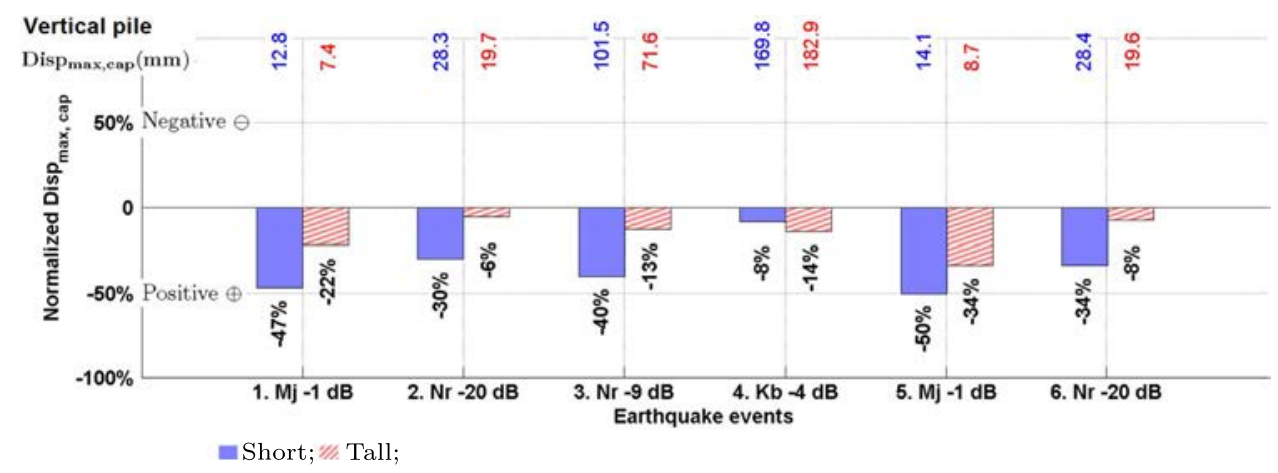

Fig. 17. Normalized maximum displacements of the pile cap (prototype scale). 


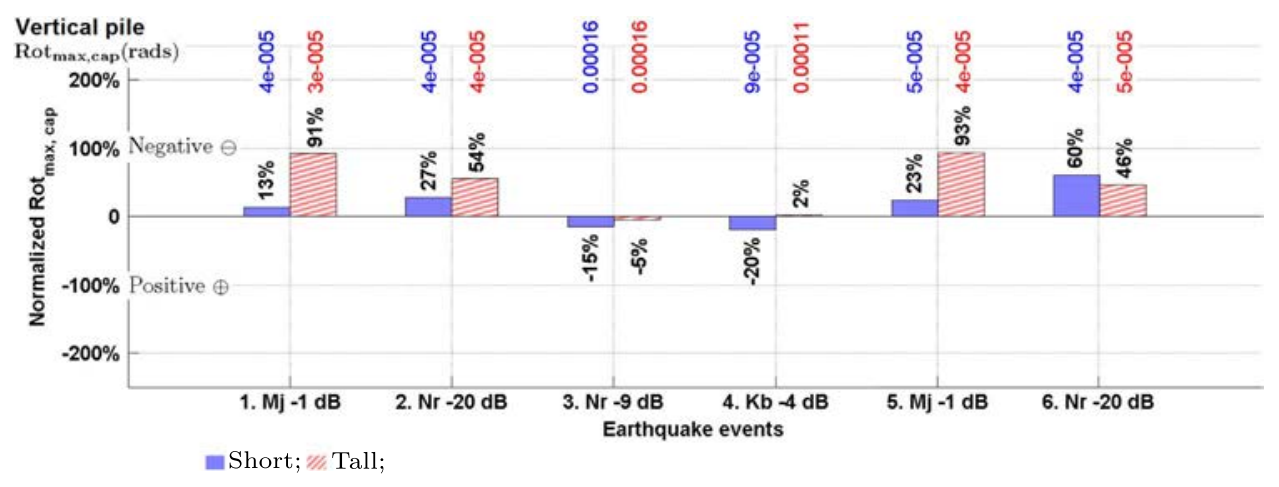

Fig. 18. Normalized maximum rotations of the pile cap.

Table 6

Ratios of overturning moment to base shear for the different configurations.

\begin{tabular}{|c|c|c|c|c|c|c|c|}
\hline \multicolumn{2}{|c|}{ Configurations } & \multirow{2}{*}{$\begin{array}{l}\text { 1. } \mathrm{Mj} \\
-1 \mathrm{~dB}\end{array}$} & \multirow{2}{*}{$\begin{array}{l}\text { 2. } \mathrm{Nr} \\
-20 \mathrm{~dB}\end{array}$} & \multirow{2}{*}{$\begin{array}{l}\text { 3. } \mathrm{Nr} \\
-9 \mathrm{~dB}\end{array}$} & \multirow{2}{*}{$\begin{array}{l}\text { 4. } \mathrm{Kb} \\
-4 \mathrm{~dB}\end{array}$} & \multirow{2}{*}{$\begin{array}{l}\text { 5. } \mathrm{Mj} \\
-1 \mathrm{~dB}\end{array}$} & \multirow{2}{*}{$\begin{array}{l}\text { 6. } \mathrm{Nr} \\
-20 \mathrm{~dB}\end{array}$} \\
\hline IS & 氶 & & & & & & \\
\hline VS & 虽 & 3.90 & 3.44 & 4.35 & 4.60 & 3.81 & 3.36 \\
\hline IT & $\frac{1}{4}$ & 7.06 & 6.46 & 6.57 & 6.86 & 5.89 & 6.21 \\
\hline VT & $\frac{T}{4}$ & 8.33 & 9.19 & 6.95 & 6.91 & 8.59 & 7.48 \\
\hline
\end{tabular}

kinematic and inertial interactions are analyzed and discussed. The envelope curves of the maximum stresses and the normalized peak values are compared for the different pile groups and superstructure configurations.

\subsubsection{Residual bending moments}

Fig. 21 shows the accumulated residual bending moment profiles along the piles for successive earthquake events. The presence of batter piles influences the shape of the profiles inducing in general a " $C$ " and not the " $\mathrm{S}$ " shape profile obtained for vertical pile groups. For both pile group configurations, the height of the superstructure affects the depth of the maximum residual bending moment. For a short superstructure, batter piles increase this depth from $4 D$ to $6 D$ during the first two small earthquakes. This depth however remains unchanged during and after the strong earthquakes.

Concerning the maximum values of the residual bending moment, as shown in Fig. 22, batter piles have a detrimental effect regardless the type of the supported superstructure. However, the height of the superstructure, the base shaking characteristics and the loading history influence the effect of the batter piles. Once the residual bending moment was developed during the strong earthquakes, the subsequent small earthquakes cannot induce additional residual bending moments. This detrimental behavior is more pronounced when a tall superstructure is supported , except for the strong 3rd Northridge earthquake.

\subsubsection{Maximum bending moments}

Fig. 23 shows the normalized maximum bending moment profiles. Because of the presence of the residual bending moments, the curves for subsequent earthquakes are dragged and distorted in an asymmetric way. As a consequence, a " $\mathrm{C}$ " shape is still noticeable for the batter pile group. However, it is difficult to precisely describe the shape of the bending moment envelope curves for the vertical pile group. In general, the maximum values of the total bending moments for the vertical pile group are equally important below and above the soil surface. It is also observed that batter piles result in a reduction of the bending moment at the pile head. This observation is not in accordance with the results obtained on micropiles by Juran et al. [26] where higher bending moments were found at the pile head connections. This difference may due to the different superstructure configurations. In the tests performed by Juran et al. [26], only a pile cap was considered as a superstructure. However, in this paper, two more slender (short and tall) superstructures are used. It may also due to a different ratio of pull out resistance over bending moment resistance of the pile (the micropiles used by Juran had lower bending moment resistance).

Fig. 24 presents the normalized maximum total bending moments. In general, batter piles reduce the maximum total bending moment. This effect is more pronounced for the case of a short superstructure with a small ratio of OM/BS. When a short superstructure is supported, the performance of batter piles seems to be not influenced by the frequency content of the base shaking signals. For the case of a tall superstructure, the performance of batter piles is influenced by the base shaking characteristics.

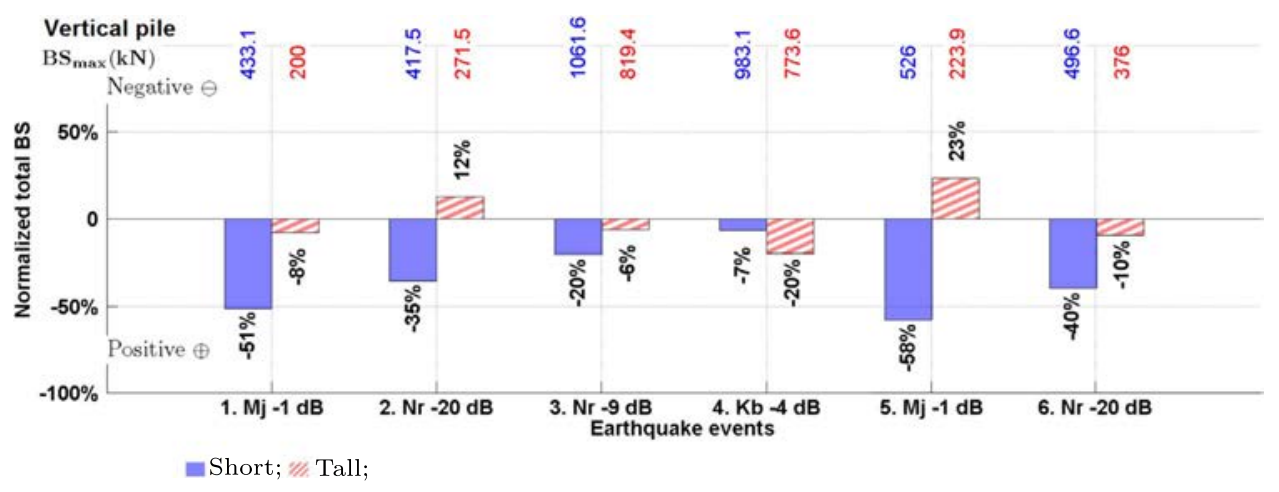

Fig. 19. Normalized maximum total base shear forces (prototype scale). 


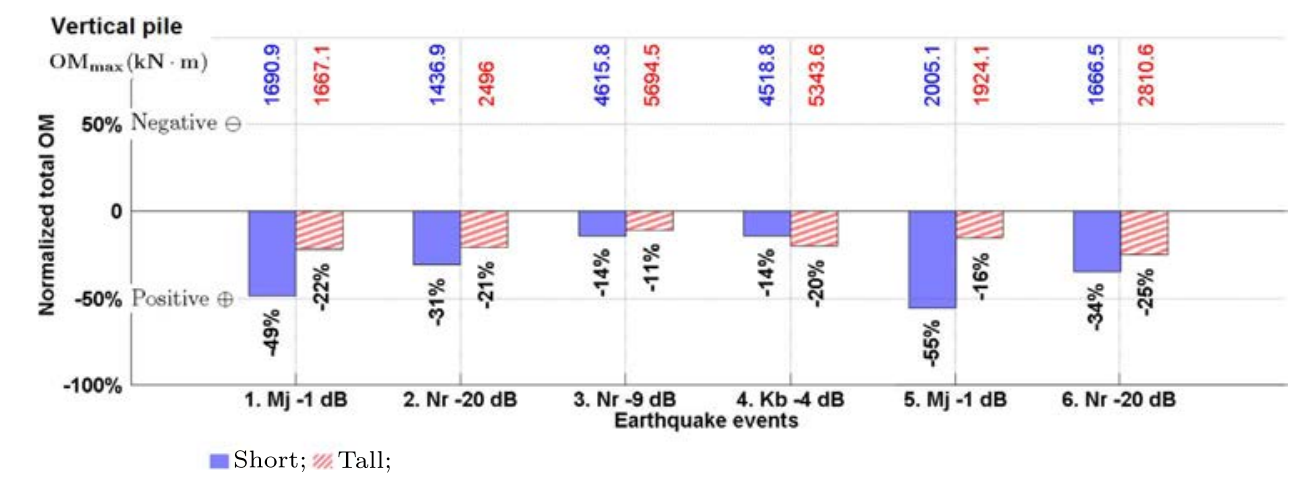

Fig. 20. Normalized maximum total overturning moments (prototype scale).

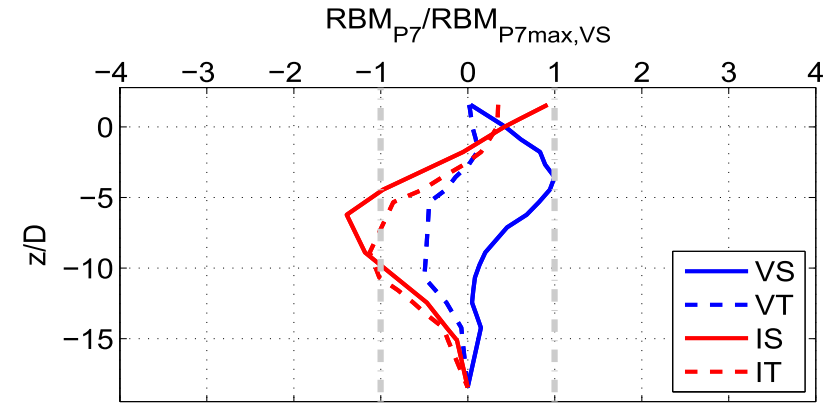

Martinique Jara $-1 \mathrm{~dB}$

(a)

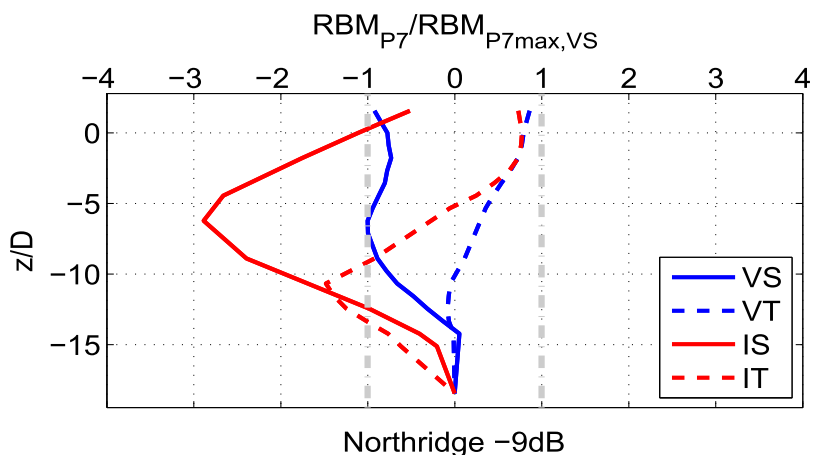

(c)

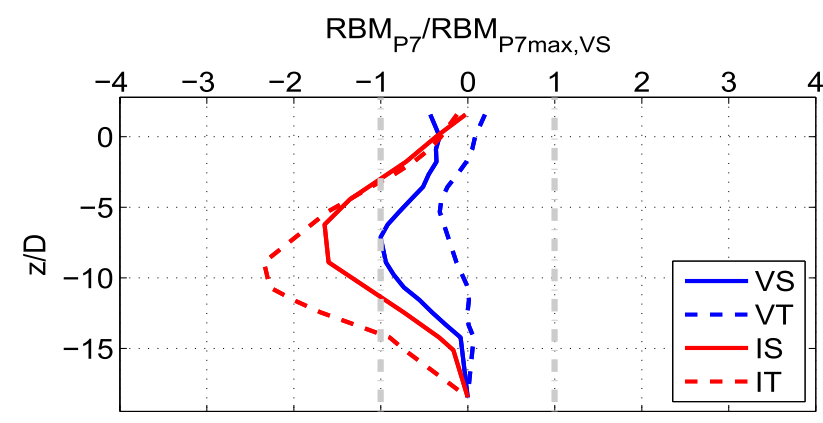

Martinique Jara $-1 \mathrm{~dB}$

(e)

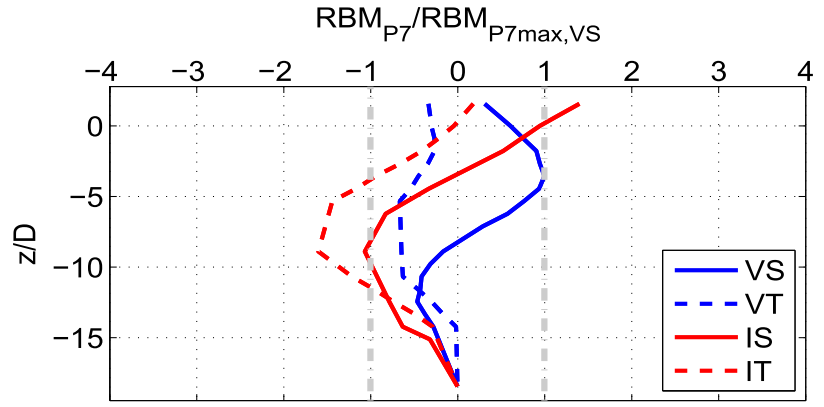

Northridge $-20 \mathrm{~dB}$

(b)

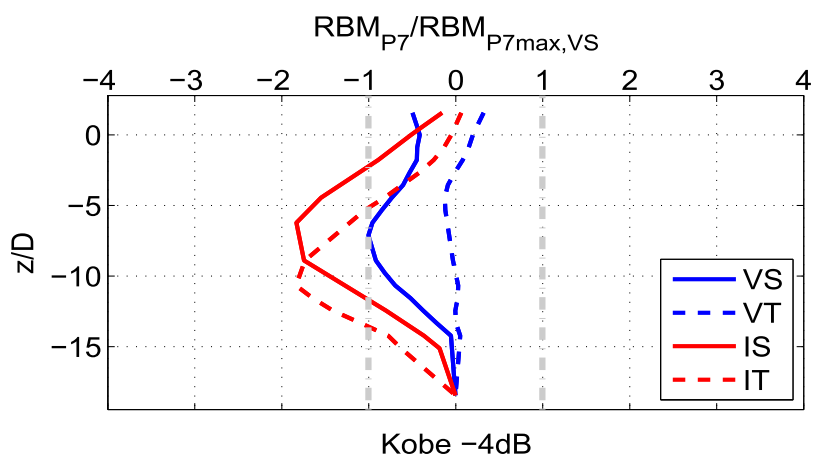

(d)

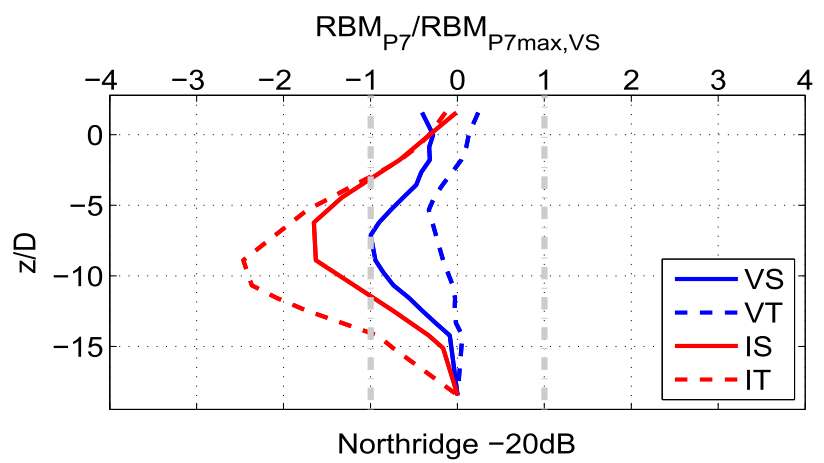

(f)

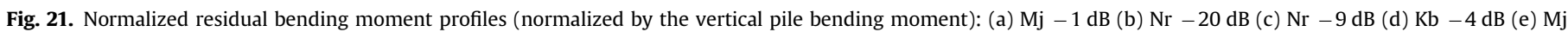
$-1 \mathrm{~dB}$ (f) $\mathrm{Nr}-20 \mathrm{~dB} . z$ is the depth below ground surface. 


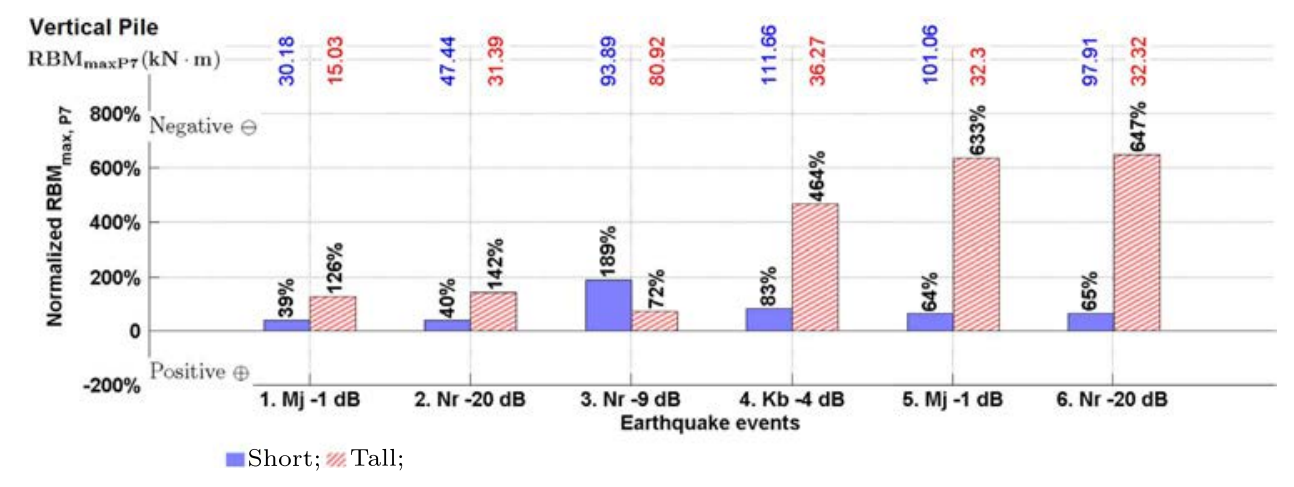

Fig. 22. Normalized maximum residual bending moments (prototype scale).

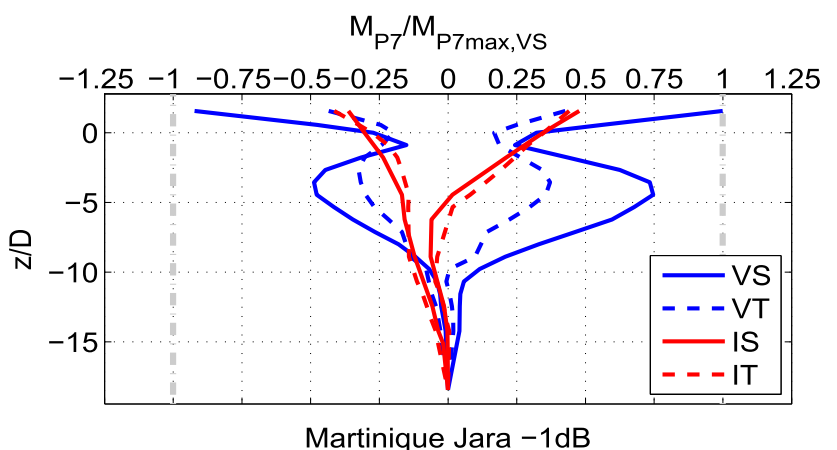

(a)

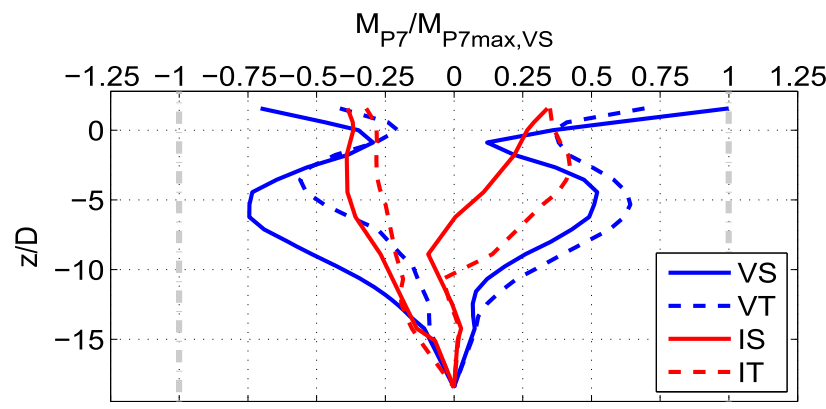

Northridge $-9 d B$

(c)

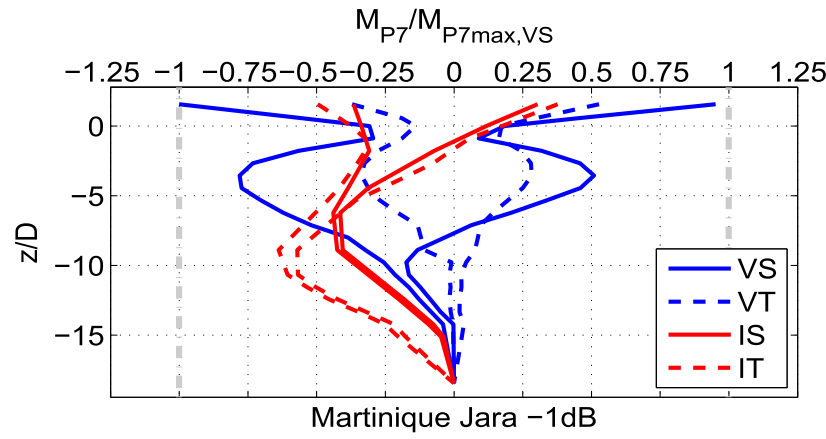

(e)

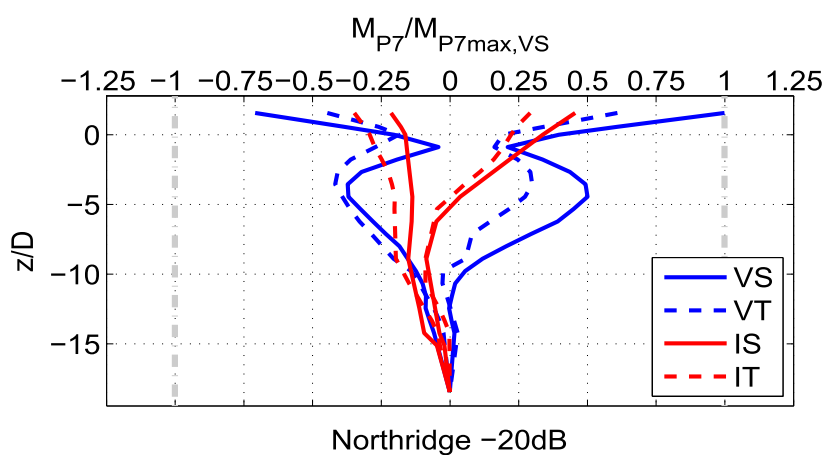

(b)

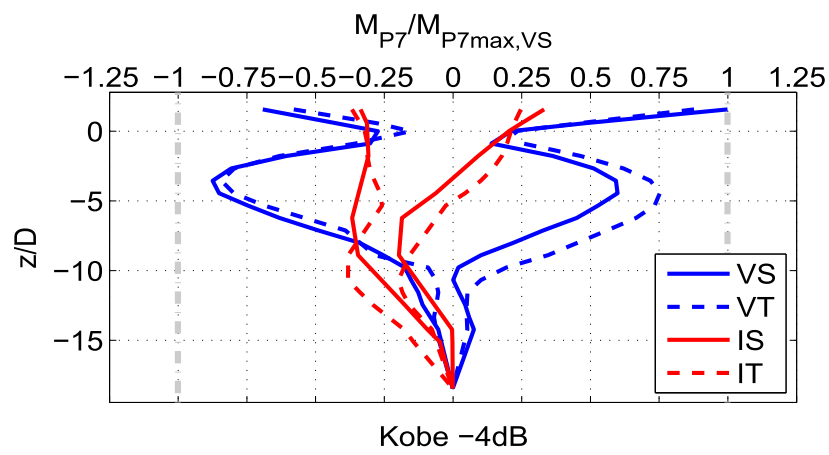

(d)

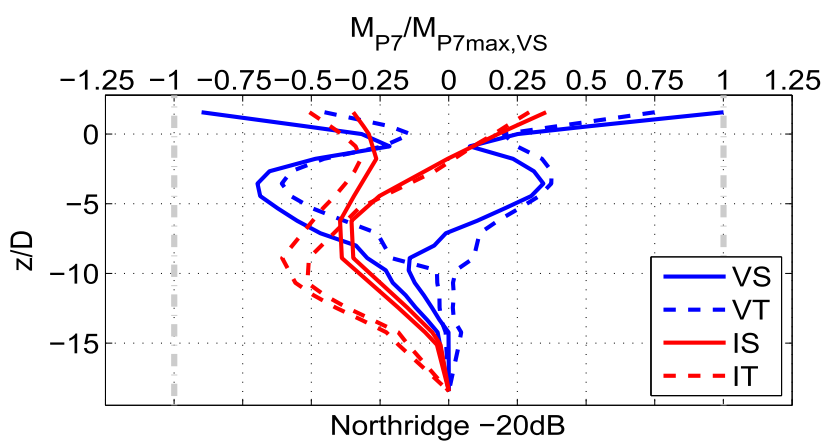

(f)

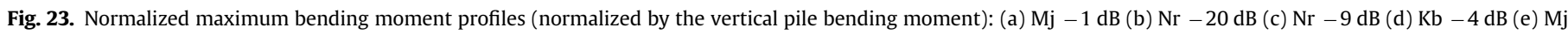
$-1 \mathrm{~dB}$ (f) $\mathrm{Nr}-20 \mathrm{~dB} . z$ is the depth below ground surface.

\subsubsection{Axial forces}

Since only 3 strain gauges were used to measure the axial force, it was not possible to identify the axial force profiles. The maximum total axial force is discussed hereafter (no important residual effects were observed). The distance between the bottom of the pile cap and the soil surface remained almost the same 


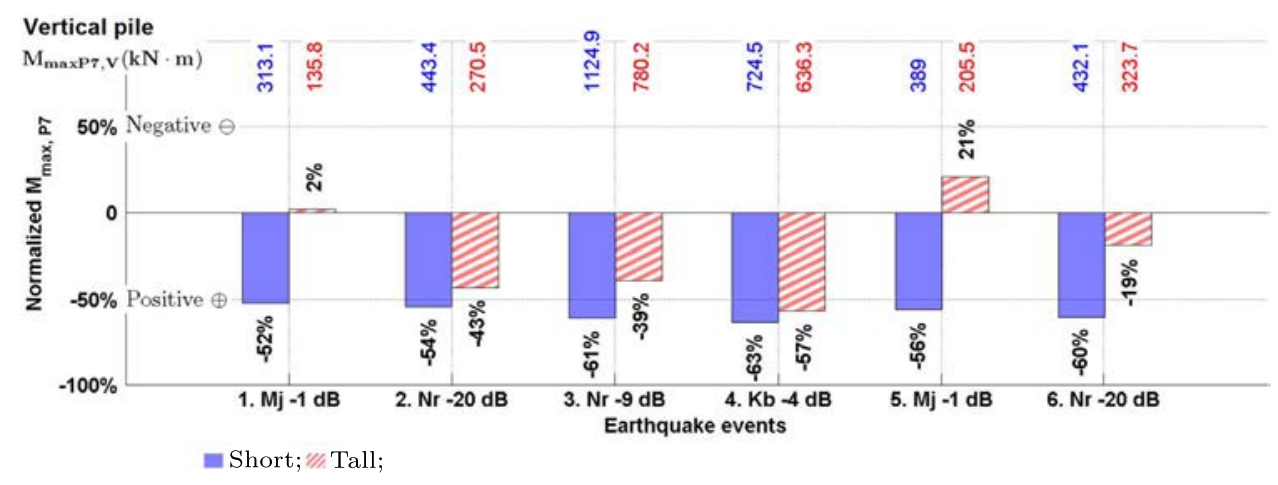

Fig. 24. Normalized maximum total bending moments (prototype scale).

before and after the test, no obvious relative displacement was observed in the axial direction. According to Nazir and Nasr [41], in dense sand, within a small range of axial displacement, piles did not exceed their axial capacities. Similar to the total bending moments, batter piles often reduce the maximum axial force (Fig. 25). This effect is however relatively small (most of the time less than 30\%) and is influenced by the frequency content and the amplitude of the base signal. For the case of a tall superstructure, the beneficial role of batter piles is less influenced. This reduction effect of batter piles on the axial forces could due to the presence of the superstructures, since it has been shown in Sections 4.3 and 4.4 that, in general, the batter pile-superstructure systems attract less base shear forces and overturning moments.

\section{Overall behavior}

The overall experimental behavior of batter and vertical pile foundations with short and tall superstructures under successive earthquake excitations can be summarized as follows:

1. The presence of batter piles contributes to a higher horizontal stiffness (comparing to the vertical pile configuration) and thus causes an increase of the corresponding frequencies.

2. An increase of the height of the center of gravity (C.G.) of the superstructure amplifies the influence of the Seismic Soil-PileSuperstructure Interaction (SSPSI) on the frequency response for both pile group configurations. The influence of the C.G. is more pronounced for batter piles.

3. Batter piles decrease the horizontal pile cap displacements. This effect is influenced by the characteristics of the base shaking signal and it is more pronounced for short superstructures.

4. Batter piles tend to induce higher pile cap rotations for small earthquakes, especially for tall superstructures. This may due to the shear interface stiffness along batter piles is less than the vertical pile cap rotational stiffness. However for strong earthquakes batter piles play a beneficial role in decreasing the pile cap rotations, especially for short superstructures. This effect may due to the more important nonlinear behavior of the soil developed during strong earthquakes.

5. Batter piles tend to decrease the total overturning moment and the total base shear, especially for short superstructures.

6 . The use of batter piles induces higher residual bending moments. This detrimental performance is more pronounced for tall superstructures. Batter piles also influence the shape of the residual bending moment profiles.

7. Batter piles reduce the total bending moment. This beneficial performance is not so much influenced by the characteristics of the base shaking signal for the case of short superstructures.

8. Batter piles reduce the axial forces. This effect is probably due to the batter pile-superstructure systems that attract less base shear forces and overturning moments. This beneficial effect is less influenced by the characteristics of base shaking signal for the case of tall superstructures.

In general, batter piles supporting short superstructures i.e. where inertial shear forces dominate, seem to have a more significant beneficial effects.

\section{Conclusions}

In this paper, an experimental dynamic centrifuge modeling campaign is presented to study the behavior of pile foundations considering Seismic Soil-Pile-Superstructure Interaction (SSPSI). This study enriches the database of the effect of batter piles on the seismic response of pile group. The influence of the height of gravity center on the performances of batter piles is highlighted. Cross comparisons are carried out to investigate the performance of different pile foundations with vertical or batter piles, short or

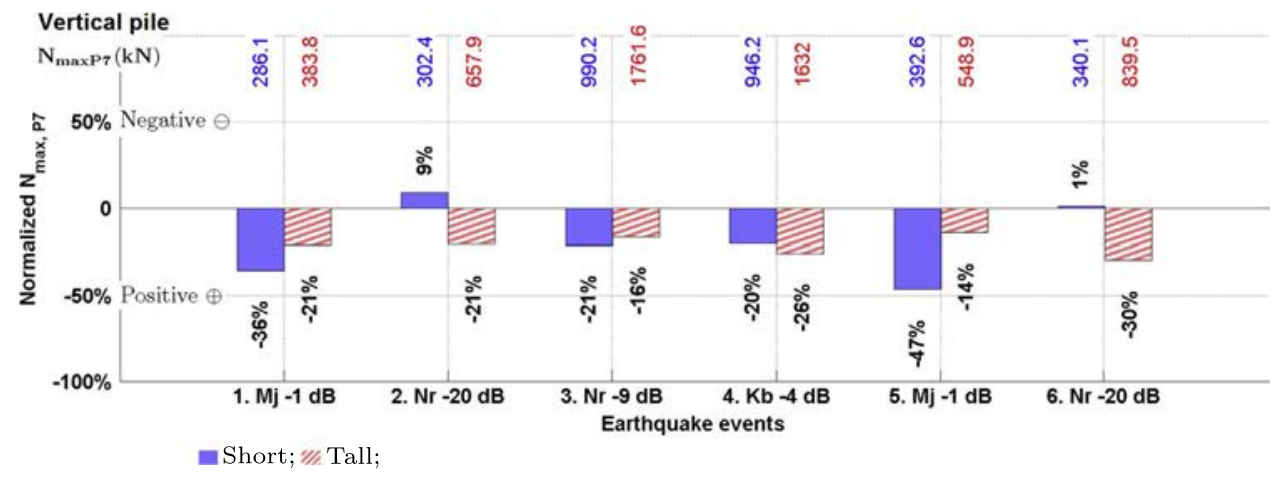

Fig. 25. Normalized maximum axial forces (prototype scale). 
tall superstructures and various earthquake loadings. Although the use of batter piles seems to have in general a positive effect in terms of displacements and total forces, it is found that the performance can vary depending on the characteristics of the base shaking signal and of the height of the center of gravity of the supported superstructures.

This paper extends the work of Li et al [42] to more general real earthquake loading and the results confirm the conclusions that batter piles are likely to have beneficial performance. In addition, these beneficial effects are more often observed for batter piles with a short superstructure. In order to be able to predict the beneficial or detrimental behavior of vertical and batter pile foundations, simplified numerical models based on the macroelement approach $[43,44]$ have been recently developed to simulate the nonlinear behavior of pile foundations.

The initial stress state of the batter piles could also significantly influence their performance, which should attract attentions in future experimental and numerical campaigns.

\section{Acknowledgments}

The financial support of IFSTTAR (Institut français des sciences et technologies des transports, de l'aménagement et des réseaux) and of the Région Pays de la Loire is gratefully acknowledged. The authors would like also to thank the valuable support and help from the technical staff of the IFSTTAR centrifuge team.

\section{References}

[1] AFPS. Recommandations AFPS 90. Presses des Ponts et Chaussées; 1990.

[2] Eurocode8. Eurocode 8: design of structures for earthquake resistance-Part 5: foundations, retaining structures and geotechnical aspects. Belgium: European Committee for Standardization (CEN); 2004.

[3] Gerolymos N, Giannakou A, Anastasopoulos I, Gazetas G. Evidence of beneficial role of inclined piles: observations and summary of numerical analyses. Bull Earthq Eng 2008;6(4):705-22. http://dx.doi.org/10.1007/ s10518-008-9085-2.

[4] Gazetas G, Mylonakis G. Seismic soil-structure interaction: new evidence and emerging issues. In: Proceedings of geotechnical earthquake engineering and soil dynamics III; 1998. p. 1119-74.

[5] Pender MJ. Aseismic pile foundation design analysis. Bull N Z Soc Earthq Eng 1993;26(1):49-160.

[6] Berrill JB, Christensen SA, Keenan RP, Okada W, Pettinga JR. Case study of lateral spreading forces on a piled foundation. Géotechnique 2001;51(6):50117. http://dx.doi.org/10.1680/geot.2001.51.6.501.

[7] Harn R. Have batter piles gotten a bad rap in seismic zones (or everything you wanted to know about batter piles but were afraid to ask). In: Proceedings of Ports 2004: port development in the changing world; 2004. p. 1-10. 〈http://dx. doi.org/10.1061/40727(2004)13>.

[8] Meyerhof GG, Ranjan G. The bearing capacity of rigid piles under inclined loads in sand. I: vertical piles. Can Geotech J 1972;9(4):430-46. http://dx.doi. org/10.1139/t72-043.

[9] Meyerhof GG, Ranjan G. The bearing capacity of rigid piles under inclined loads in sand. II: batter piles. Can Geotech J 1973;10(1):71-85. http://dx.doi. org/10.1139/t73-006.

[10] Meyerhof GG, Ranjan G. The bearing capacity of rigid piles under inclined loads in sand. III: pile groups. Can Geotech J 1973;10(3):428-38. http://dx.doi. org/10.1139/t73-036.

[11] Meyerhof GG, Yalcin AS, Mathur SK. Ultimate pile capacity for eccentric inclined load. J Geotech Eng 1983;109(3):408-23. http://dx.doi.org/10.1061/ (ASCE)0733-9410(1983)109:3(408).

[12] Meyerhof GG, Sastry VVRN. Bearing capacity of rigid piles under eccentric and inclined loads. Can Geotech J 1985;22(3):267-76. http://dx.doi.org/10.1139/ t85-040.

[13] Meyerhof GG, Yalcin AS. Behaviour of flexible batter piles under inclined loads in layered soil. Can Geotech J 1993;30(2):247-56. http://dx.doi.org/10.1139/ t93-021.

[14] Meyerhof GG, Yalcin AS. Bearing capacity of flexible batter piles under eccentric and inclined loads in layered soil. Can Geotech J 1994;31(4):583-90. http://dx.doi.org/10.1139/t94-068.

[15] Pinto P, McVay M, Hoit M, Lai P. Centrifuge testing of plumb and battered pile groups in sand. Transp Res Rec: J Transp Res Board 1997;1569:8-16. http://dx. doi.org/10.3141/1569-02.
[16] McVay MC, Gardner R, Zhang L. Centrifuge modeling of laterally loaded battered pile groups in sand. U. S. Department of Commerce National Technical Information Service; 1997.

[17] Zhang L, McVay MC, Lai PW. Centrifuge modelling of laterally loaded single battered piles in sands. Can Geotech J 1999;36(6):1074-84. http://dx.doi.org/ 10.1139/t99-072.

[18] Zhang LM, McVay MC, Han SJ, Lai PW, Gardner R. Effects of dead loads on the lateral response of battered pile groups. Can Geotech J 2002;39(3):561-75. http://dx.doi.org/10.1139/t02-008.

[19] Escoffier S, Chazelas JL, Garnier J. Centrifuge modelling of raked piles. Bull Earthq Eng 2008;6:689-704. http://dx.doi.org/10.1007/s10518-008-9094-1.

[20] Escoffier S. Experimental study of the effect of inclined pile on the seismic behavior of pile group. Soil Dyn Earthq Eng 2012;42:275-91. http://dx.doi.org/ 10.1016/j.soildyn.2012.06.007.

[21] Chazelas JL, Escoffier S, Garnier J, Thorel L, Rault G. Original technologies for proven performances for the new LCPC earthquake simulator. Bull Earthq Eng 2008;6(4):723-8. http://dx.doi.org/10.1007/s10518-008-9096-z.

[22] Okawa K, Kamei H, Kimura M, Zhang F. Dynamic behaviour of a group-pile foundation with inclined piles in loose sand. In: Proceedings of International conference on physical modelling in geotechnics: ICPMG'02; 2002. pp. 72934.

[23] Boland JC, Schlechter SM, McCullough NJ, Dickenson SE, Kutter BL, Wilson DW. Pile-supported Wharf centrifuge model (JCB01). Tech. Rep. October. Davis: Center for Geotechnical Modeling University of California; 2001.

[24] Boland JC, Schlechter SM, McCullough NJ, Dickenson SE, Kutter BL, Wilson DW Pile-supported Wharf centrifuge model (SMS02). Tech. Rep. October. Davis: Center for Geotechnical Modeling University of California; 2001.

[25] Schlechter S, Dickenson S, McCullough N, Boland J. Influence of batter piles on the dynamic behavior of pile-supported Wharf structures. In: Proceedings of Ports 2004: port development in the changing world. Houston, Texas, United States: American Society of Civil Engineers; 2004. pp. 1-10. 〈http://dx.doi.org 10.1061/40727(2004)12>.

[26] Juran I, Benslimane A, Hanna S. Engineering analysis of dynamic behavior of micropile system. Transp Res Rec: J Transp Res Board 2001;1772:91-106. http: //dx.doi.org/10.3141/1772-11.

[27] Giannakou AK. Seismic behavior of inclined piles [Ph.D. dissertation]. Nationa Technical University of Athens; 2007.

[28] Giannakou A, Gerolymos N, Gazetas G, Tazoh T, Anastasopoulos I. Seismic behavior of batter piles: elastic response. J Geotech Geoenviron Eng 2010;136 (9):1187-99. http://dx.doi.org/10.1061/(ASCE)GT.1943-5606.0000337.

[29] Shahrour I, Juran I. Seismic behaviour of micropile systems. Proceedings of the Institution of Civil Engineers-Ground Improvement 2004;8(3):109-20. http: //dx.doi.org/10.1680/grim.2004.8.3.109.

[30] Mokwa RL, Duncan JM. Rotational restraint of pile caps during lateral loading. J Geotech Geoenviron Eng 2003;129(9):829-37. http://dx.doi.org/10.1061/ (ASCE)1090-0241(2003)129:9(829).

[31] Beatty CI. Lateral test on pile groups. Found Facts 1970;6(1):18-21.

[32] Kim JB, Brungraber RJ, Singh LP. Pile cap soil interaction from full-scale latera load tests. J Geotech Eng Div 1979;105(5):643-53.

[33] Liu JL, Yuan ZL, Zhang KP. Cap-pile-soil interaction of bored pile groups. In: Proceedings of the eleventh international conference on soil mechanics and foundation engineering. San Francisco; 1985, p. 1433-36.

[34] Zafir Z, Vanderpool WE. Lateral response of large diameter drilled shafts: I-15 US 95 load test program. In: Proceedings of the 33rd engineering geology and geotechnical engineering symposium. Reno: University of Nevada; 1998. p. 161-76.

[35] Harris CM, Piersol AG. Harris' shock and vibration handbook.New York: McGraw-Hill; 2002.

[36] Zeng X, Schofield AN. Design and performance of an equivalent-shear-beam container for earthquake centrifuge modelling. Géotechnique 1996;46(1):83102. http://dx.doi.org/10.1680/geot.1996.46.1.83.

[37] Teymur B, Madabhushi SPG. Experimental study of boundary effects in dynamic centrifuge modelling. Géotechnique 2003;53(7):655-63. http://dx.doi org/10.1680/geot.2003.53.7.655.

[38] Arias A. A measure of earthquake intensity. In: Hansen R, editor. Seismic design for nuclear power plants. MIT Press; 1970. p. 438-83.

[39] Escoffier S. Seismic and sinusoidal tests on pile group (Tech. rep.). IFSTTAR; 2011.

[40] Li Z, Escoffier S, Kotronis P. Using centrifuge tests data to identify the dynamic soil properties: application to Fontainebleau sand. Soil Dyn Earthq Eng 2013;52:77-87. http://dx.doi.org/10.1016/j.soildyn.2013.05.004.

[41] Nazir A, Nasr A. Pullout capacity of batter pile in sand. J Adv Res 2013;4 (2):147-54. http://dx.doi.org/10.1016/j.jare.2012.04.001.

[42] Li Z, Escoffier S, Kotronis P. Centrifuge modeling of batter pile foundations under sinusoidal dynamic excitation. Bull Earthq Eng 2016;14(3):673-97. http://dx.doi.org/10.1007/s10518-015-9859-2.

[43] Li Z, Kotronis P, Escoffier S. Numerical study of the 3D failure envelope of a single pile in sand. Comput Geotech 2014;62:11-26. http://dx.doi.org/10.1016 j.compgeo.2014.06.004.

[44] Li Z, Kotronis P, Escoffier S, Tamagnini C. A hypoplastic macroelement for single vertical piles in sand subject to three-dimensional loading conditions. Acta Geotech 2016;11(2):373-90. http://dx.doi.org/10.1007/ s11440-015-0415-7. 